Supporting Information

\title{
Ring-opening metathesis polymerization of unsaturated carbohydrate derivatives: levoglucosenyl alkyl ethers
}

\author{
Tapas Debsharma, ${ }^{a}$ Bernd Schmidt, ${ }^{a}$ André Laschewsky, ${ }^{a, b}$ Helmut Schlaada* \\ a University of Potsdam, Institute of Chemistry, Karl-Liebknecht-Straße 24-25, 14476 Potsdam, \\ Germany. ${ }^{b}$ Fraunhofer Institute of Applied Polymer Research IAP, Geiselbergstraße 69, \\ 14476 Potsdam, Germany.
}

\section{Analytical instrumentation}

Nuclear Magnetic Resonance (NM R) spectra were recorded on Bruker Avance Neo $400 \mathrm{M} \mathrm{Hz}$, Bruker Avance $500 \mathrm{M} \mathrm{Hz}$ or Bruker Avance III $600 \mathrm{M} \mathrm{Hz}$ spectrometers at room temperature. The signals were referenced to the solvent peak at $\delta\left({ }^{1} \mathrm{H}\right) 7.26 \mathrm{ppm}$ and $\left({ }^{13} \mathrm{C}\right) 77.16 \mathrm{ppm}$ for $\mathrm{CDCl}_{3}, \delta\left({ }^{1} \mathrm{H}\right) 5.32 \mathrm{ppm}$ and $\left.{ }^{13} \mathrm{C}\right) 53.84 \mathrm{ppm}$ for $\mathrm{CD}_{2} \mathrm{Cl}_{2}$, and $\delta\left({ }^{1} \mathrm{H}\right) 2.50 \mathrm{ppm}$ and $\left({ }^{13} \mathrm{C}\right) 39.52 \mathrm{ppm}$ for DMSO-d 6 . In situ ${ }^{1} \mathrm{H}$ NM R measurements were recorded on a Bruker Avance $\mathrm{Neo} 400 \mathrm{M} \mathrm{Hz}$ at room temperature. Samples were prepared in 1,4-dioxane-d 8 ( $\delta 3.53 \mathrm{ppm})$ to which hexamethyldisilane (HMD) ( $\delta 0 \mathrm{ppm}$ ) was added as internal standard.

Electrospray Ionization Mass Spectrometry (ESI-MS) in positive ionization mode was measured on a Bruker micrOTOF ESI spectrometer. Samples were prepared in analytical grade methanol.

Size exclusion chromatography (SEC) with simultaneous UV and RI detection was performed with THF as the eluent (flow rate of $0.5 \mathrm{~mL} \mathrm{~min}^{-1}$ ) at room temperature. The stationary phase was a $300 \times 8 \mathrm{~mm}^{2}$ PSS SDV linear M column ( $3 \mu \mathrm{m}$ particle size, molar mass range $10^{2}-10^{6} \mathrm{Da}$ ). Solutions containing $\sim 0.15$ wt $\%$ polymer were filtered through $0.45 \mu \mathrm{m}$ PTFE filters; the injected volume was $100 \mu \mathrm{L}$. Polystyrene standards (PSS, Mainz, Germany) were used for calibration.

Thermogravimetric analysis (TGA) was performed with a M ettler Toledo TGA/SDTA851 in a temperature range from 25 to $900{ }^{\circ} \mathrm{C}$ at a heating rate of $10{ }^{\circ} \mathrm{C} \mathrm{min}-1$ under a continuous nitrogen flow of 20 $\mathrm{mL} \min ^{-1}$.

Differential scanning calorimetry (DSC) was measured on a M ettler Toledo DSC822e in a temperature range from -80 to $150{ }^{\circ} \mathrm{C}$ under a continuous nitrogen flow of $20 \mathrm{~mL} \mathrm{~min}^{-1}$. Glass transition temperatures were determined from the third heating curves at a heating rate of $30^{\circ} \mathrm{C} \mathrm{min}^{-1}$.

\section{Chemicals}

Levoglucosenone (CAS number 37112-31-5, 99.3\% purity) and dihydrolevoglucosenone (Cyrene ${ }^{\mathrm{TM}}$, 99.5\%) were provided by Circa Group Ltd, Australia. Sodium borohydride (98\%), sodium hydride (60\% dispersion in mineral oil), iodomethane (99\%), iodoethane (99\%), 1-iodopropane (99\%), 1-bromobutane $(99 \%)$, tetrabutylammonium iodide $(98 \%)$, ethyl vinyl ether $(99 \%), 1,4$-dioxane $(99.8 \%$, anhydrous), 2-methyltetrahydrofuran (2-MeTHF, 99\%, anhydrous), and ethyl acetate $(99.8 \%$, anhydrous) were purchased from Acros Chemicals. Grubbs catalyst C793 [1,3-bis-(2-methylphenyl)-2imidazolidinylidene]-dichloro(benzylidene)-(tricyclohexylphosphine)ruthenium(II) (CAS number 927429-60-5), 2-iodopropane (99\%), tetrahydrofuran (THF, 99.5\% anhydrous), and dimethylsulfoxide$\mathrm{d}_{6}(99.8 \% \mathrm{D})$ were purchased from Sigma-Aldrich. Dichloromethane (DCM, analytical grade), methanol (analytical grade), and cyclohexane (analytical grade) were purchased from Fischer Scientific. Dichloromethane- $d_{2}(99.6 \% D)$ and chloroform- $d(99.8 \% D)$ were purchased from Deutero $\mathrm{GmbH}$ and 1,4-dioxane $d_{8}(99 \% D)$ from euriso-top. 

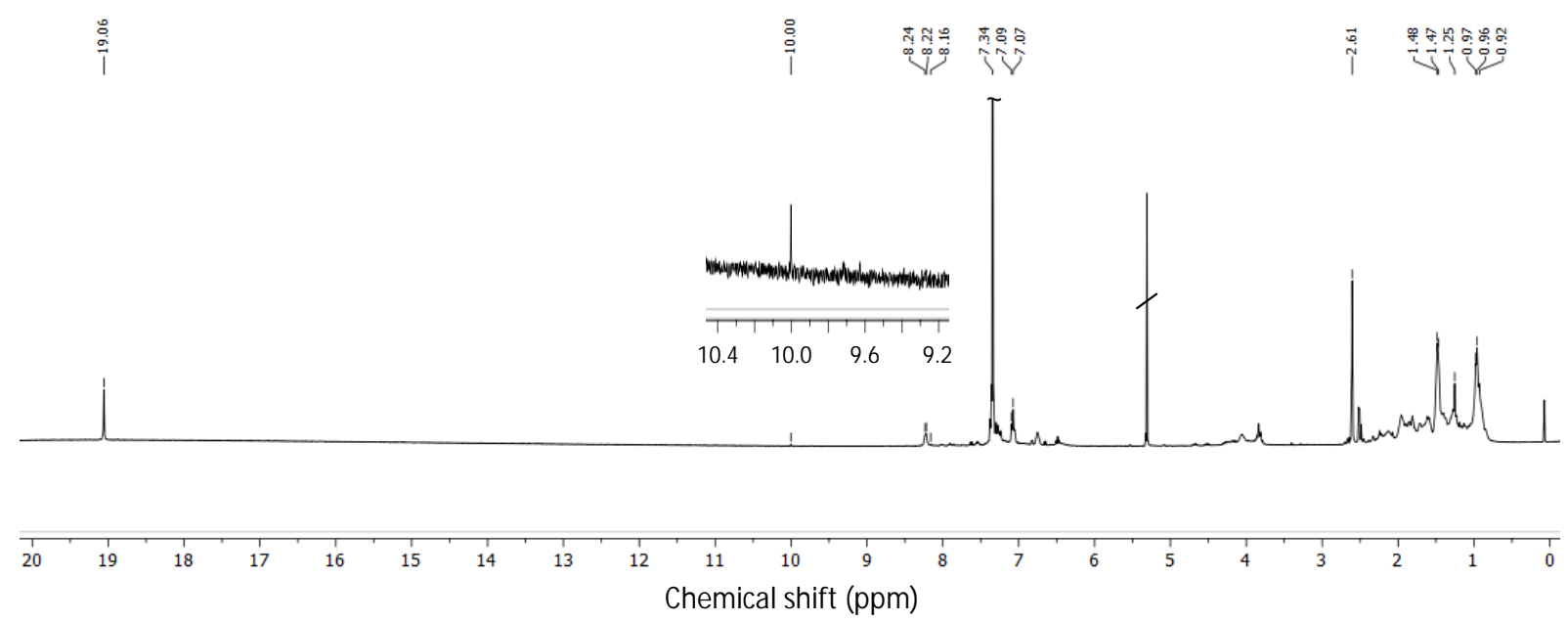

Figure S1. ${ }^{1} \mathrm{H}$ NMR (400 M Hz) spectrum of the Grubbs catalyst $\mathrm{C} 793$ in $\mathrm{CD}_{2} \mathrm{Cl}_{2}$.

\section{Monomer syntheses}

Levoglucosenone $\mathbf{1} \rightarrow$ Levoglucosenol $\mathbf{2} \mathbf{a} \rightarrow$ Levoglucosenyl methyl ether $\mathbf{2 b}$. See Angew. Chem. Int. Ed. 2019, 58 (20), 6718-6721 and Angew. Chem. Int. Ed. 2019, 58 (51), 18492-18495.

Levoglucosenyl ethyl ether $2 \mathrm{c}$. $1.5 \mathrm{~g}$ of $\mathrm{NaH}$ (60\% dispersion in mineral oil) was placed in a dry flask fitted with a septum and washed three times with dry cyclohexane. Dry THF (30 mL) was added and the mixture was cooled in an ice bath with constant stirring. A solution of levoglucosenol $(3.2 \mathrm{~g})$ in 30 $\mathrm{mL}$ of dry THF was added to the mixture and after the effervescence stopped, a solution of iodoethane ( $4.1 \mathrm{ml}, 2$ equiv) in $20 \mathrm{~mL}$ of dry THF ( $20 \mathrm{~mL}$ ) was added. The mixture was stirred at room temperature until TLC (Thin Layer Chromatography) showed complete consumption of the levoglucosenol. The crude mixture was poured into ice-cold water and extracted with DCM several times. The DCM portions were combined and evaporated in a rotary evaporator. The crude product was distilled in a Kugelrohr apparatus at $140{ }^{\circ} \mathrm{C}$ under reduced pressure $(0.1 \mathrm{mbar})$ to obtain levoglucosenyl ethyl ether as colorless liquid (3.6 g), overall yield: $91 \%$. ${ }^{1} \mathrm{H} \mathrm{NMR}\left(500 \mathrm{M} \mathrm{Hz}, \mathrm{CDCl}_{3}\right) \delta 6.02$ (ddd, J =10.0, 4.2, $1.5 \mathrm{~Hz}$, $1 \mathrm{H}), 5.66(\mathrm{dt}, \mathrm{J}=9.9,2.2 \mathrm{~Hz}, 1 \mathrm{H}), 5.55(\mathrm{t}, \mathrm{J}=2.4 \mathrm{~Hz}, 1 \mathrm{H}), 4.57(\mathrm{t}, \mathrm{J}=4.1 \mathrm{~Hz}, 1 \mathrm{H}), 4.12(\mathrm{tt}, \mathrm{J}=2.5,1.4 \mathrm{~Hz}$, $1 \mathrm{H}), 3.91(\mathrm{~d}, \mathrm{~J}=6.6 \mathrm{~Hz}, 1 \mathrm{H}), 3.71(\mathrm{ddd}, \mathrm{J}=6.5,4.1,1.2 \mathrm{~Hz}, 1 \mathrm{H}), 3.59(\mathrm{qd}, \mathrm{J}=7.0,3.7 \mathrm{~Hz}, 2 \mathrm{H}), 1.19(\mathrm{t}, \mathrm{J}=$ $7.0 \mathrm{~Hz}, 3 \mathrm{H}) .{ }^{13} \mathrm{C}$ NMR $\left(126 \mathrm{MHz}, \mathrm{CDCl}_{3}\right) \delta 130.64,126.85,100.35,77.41,77.16,76.91,76.75,71.66$, $71.61,65.02,15.69$. ESI-M S [M-H] ${ }^{+} \mathrm{m} / \mathrm{z} 157.0870$ (calc. $\mathrm{C}_{8} \mathrm{H}_{12} \mathrm{O}_{3}$ 156.088).

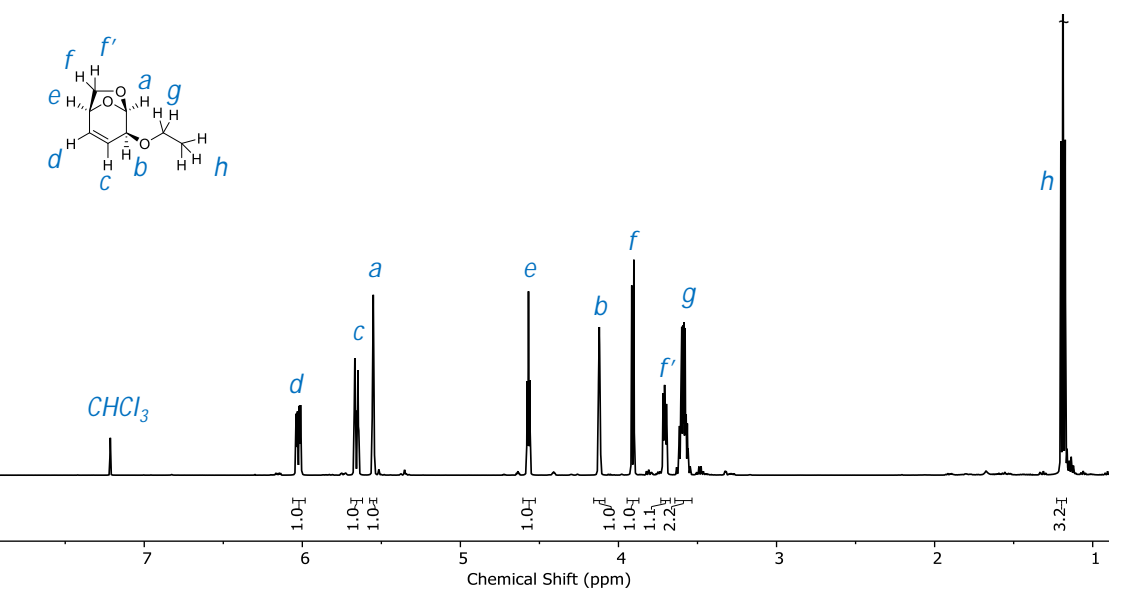

Figure S2. ${ }^{1} \mathrm{H}$ NMR (500 M Hz) spectrum of levoglucosenyl ethyl ether $\mathbf{2} \mathrm{c}$ in $\mathrm{CDCl}_{3}$. 


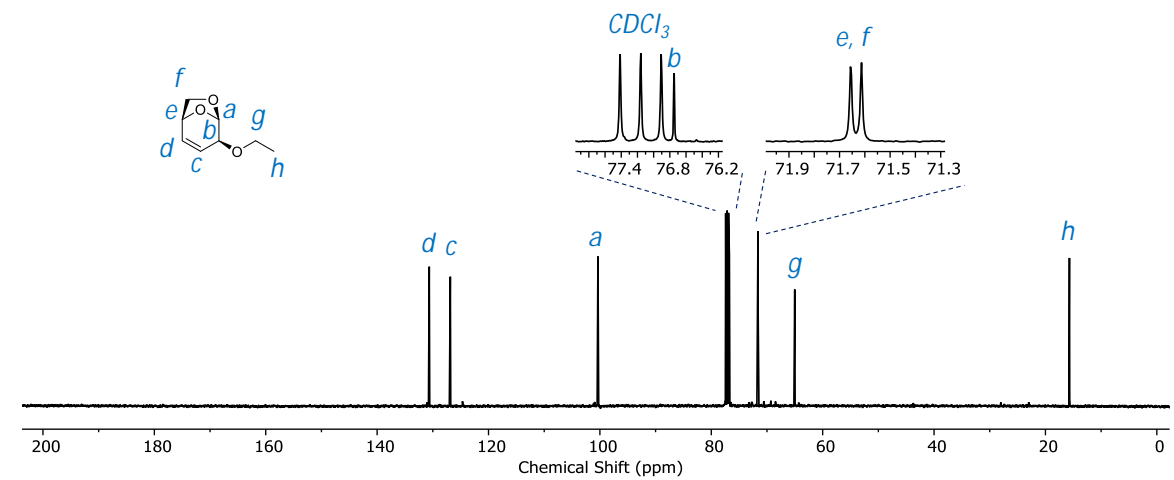

Figure S3. ${ }^{13} \mathrm{C}$ NM R (126 M Hz) spectrum of levoglucosenyl ethyl ether $\mathbf{2} \mathbf{c}$ in $\mathrm{CDCl}_{3}$.

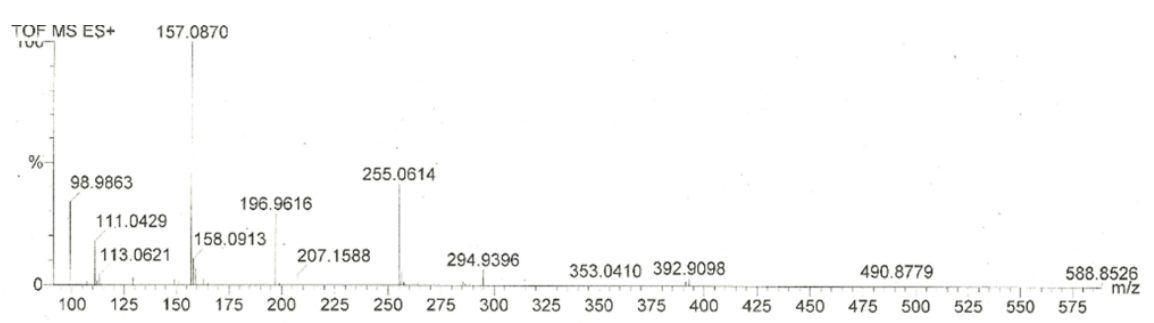

Figure S4. ESI-M S spectrum of levoglucosenyl ethyl ether $\mathbf{2 c}$.

Levoglucosenyl n-propyl ether $\mathbf{2 d}$. $1.5 \mathrm{~g}$ of $\mathrm{NaH}$ (60\% dispersion in mineral oil) was placed in a dry flask fitted with a septum and washed three times with dry cyclohexane. Dry THF (30 mL) was added and the mixture was cooled in an ice bath with constant stirring. A solution of levoglucosenol $(3.2 \mathrm{~g})$ in 30 $\mathrm{mL}$ of dry THF was added to the mixture and after the effervescence stopped, a solution of 1iodopropane ( $7.3 \mathrm{ml}, 3$ equiv) in $20 \mathrm{~mL}$ of dry THF was added. The mixture was stirred at room temperature until TLC showed complete consumption of the levoglucosenol. The crude mixture was poured into ice-cold water and extracted with DCM several times. The DCM portions were combined and evaporated in a rotary evaporator. The crude product was purified by column chromatography (ethyl acetate:cyclohexane 1:10 v/v) to obtain levoglucosenyl n-propyl ether as colorless liquid ( $3.4 \mathrm{~g}$ ), overall yield: $81 \%$. ${ }^{1} \mathrm{H} \mathrm{NM} \mathrm{R}\left(400 \mathrm{M} \mathrm{Hz}, \mathrm{CDCl}_{3}\right) \delta 6.02$ (ddd, J =9.9, 4.2, $\left.1.4 \mathrm{~Hz}, 1 \mathrm{H}\right), 5.66$ (dt, J =9.9, 2.2 $\mathrm{Hz}, 1 \mathrm{H}), 5.55(\mathrm{t}, \mathrm{J}=2.3 \mathrm{~Hz}, 1 \mathrm{H}), 4.57(\mathrm{t}, \mathrm{J}=4.1 \mathrm{~Hz}, 1 \mathrm{H}), 4.11(\mathrm{bs}, 1 \mathrm{H}), 3.91(\mathrm{~d}, \mathrm{~J}=6.6 \mathrm{~Hz}, 1 \mathrm{H}), 3.71$ (ddd, $\mathrm{J}=6.4,4.1,1.0 \mathrm{~Hz}, 1 \mathrm{H}), 3.54-3.42(\mathrm{~m}, 2 \mathrm{H}), 1.58(\mathrm{~h}, \mathrm{~J}=7.3 \mathrm{~Hz}, 2 \mathrm{H}), 0.87(\mathrm{t}, \mathrm{J}=7.4 \mathrm{~Hz}, 2 \mathrm{H}) .{ }^{13} \mathrm{C}$ NMR $(101$ $\left.\mathrm{MHz}, \mathrm{CDCl}_{3}\right) \delta 130.63,126.95,100.39,77.48,77.16,76.96,76.84,71.71,71.67,71.54,23.33,23.01$, 10.58. ESI-M S [M-H] ${ }^{+} \mathrm{m} / \mathrm{z} 171.1024$ (calc. $\mathrm{C}_{9} \mathrm{H}_{14} \mathrm{O}_{3}$ 170.099).

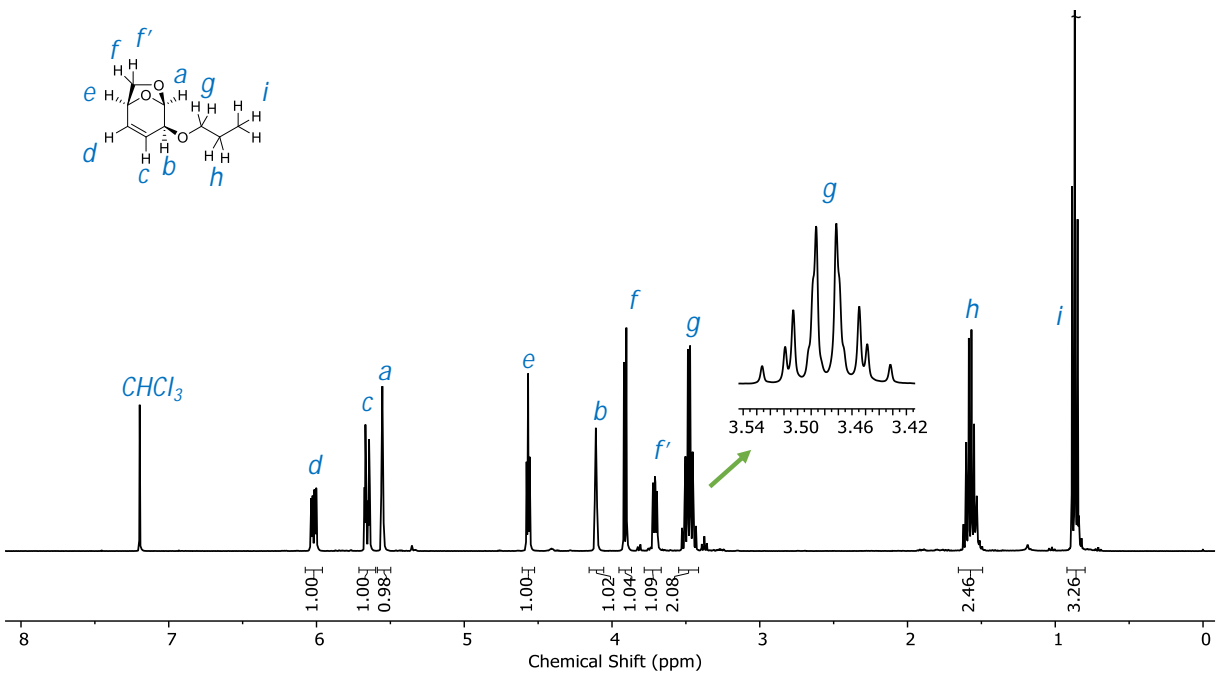

Figure S5. ${ }^{1} \mathrm{H}$ NMR (400 M Hz) spectrum of levoglucosenyl n-propyl ether $\mathbf{2} \mathbf{d}$ in $\mathrm{CDCl}_{3}$. 


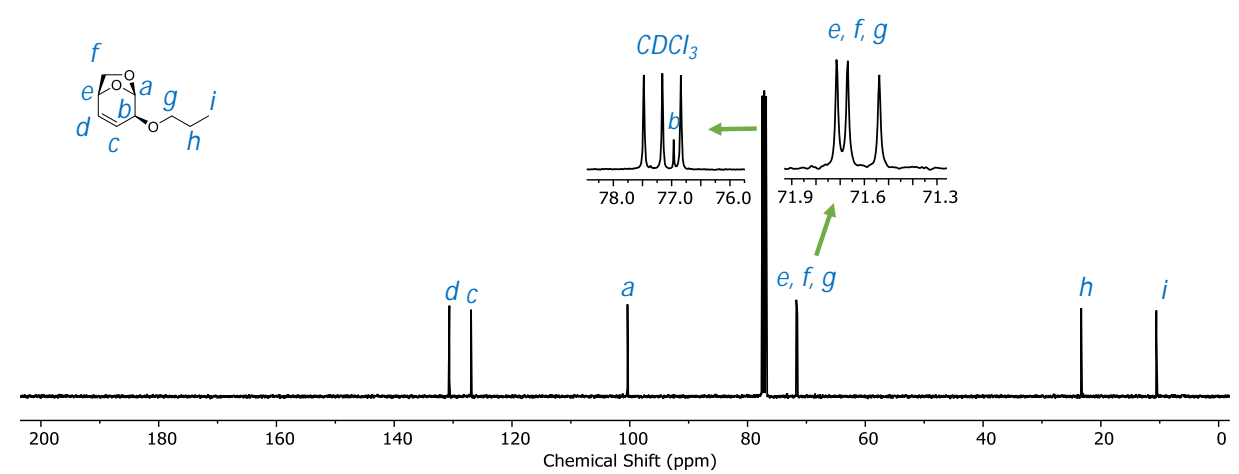

Figure S6. ${ }^{13} \mathrm{C}$ NM R (101 M Hz) spectrum of levoglucosenyl n-propyl ether $\mathbf{2} \mathbf{d}$ in $\mathrm{CDCl}_{3}$.

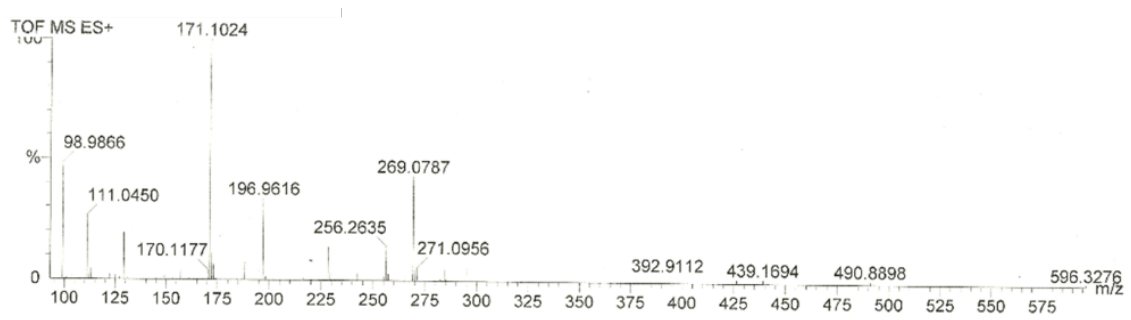

Figure S7. ESI-M S spectrum of levoglucosenyl n-propyl ether $\mathbf{2 d}$.

Levoglucosenyl isopropyl ether 2 e. $1.5 \mathrm{~g}$ of $\mathrm{NaH}$ ( $60 \%$ dispersion in mineral oil) was placed in a dry flask fitted with a septum and washed three times with dry cyclohexane. Dry THF (30 mL) was added and the mixture was cooled in an ice bath with constant stirring. A solution of levoglucosenol $(3.2 \mathrm{~g})$ in 30 $\mathrm{mL}$ of dry THF was added to the mixture and after the effervescence stopped, a solution of 2iodopropane ( $12.5 \mathrm{ml}, 5$ equiv) in $20 \mathrm{~mL}$ of dry THF was added. The mixture was stirred at room temperature until TLC showed complete consumption of the levoglucosenol. The crude mixture was poured into ice-cold water and extracted with DCM several times. The DCM portions were combined and evaporated in a rotary evaporator. The crude product was purified by column chromatography (ethyl acetate:cyclohexane 1:10 v/v) to obtain levoglucosenyl isopropyl ether as colorless liquid (2.1 g), overall yield: $50 \%$. ${ }^{1} \mathrm{H} \mathrm{NMR}\left(400 \mathrm{M} \mathrm{Hz}, \mathrm{CDCl}_{3}\right) \delta 5.98$ (ddd, J =9.9, 4.1, $\left.1.4 \mathrm{~Hz}, 1 \mathrm{H}\right), 5.59$ (dt, J = 9.9, $2.2 \mathrm{~Hz}, 1 \mathrm{H}), 5.48(\mathrm{t}, \mathrm{J}=2.3 \mathrm{~Hz}, 1 \mathrm{H}), 4.56(\mathrm{t}, \mathrm{J}=4.1 \mathrm{~Hz}, 1 \mathrm{H}), 4.17(\mathrm{~s}, 1 \mathrm{H}), 3.92(\mathrm{~d}, \mathrm{~J}=6.6 \mathrm{~Hz}, 1 \mathrm{H}), 3.74-$ $3.66(\mathrm{~m}, 2 \mathrm{H}), 1.15(\mathrm{t}, \mathrm{J}=6.1 \mathrm{~Hz}, 5 \mathrm{H}) .{ }^{13} \mathrm{C} \mathrm{NM} \mathrm{R}\left(101 \mathrm{M} \mathrm{Hz}, \mathrm{CDCl}_{3}\right) \delta 130.26,128.05,101.02,74.95,71.68$, 71.66, 23.16, 22.91. ESI-M S [M-H] ${ }^{+} \mathrm{m} / \mathrm{z} 171.1026$ (calc. $\mathrm{C}_{9} \mathrm{H}_{14} \mathrm{O}_{3}$ 170.099).
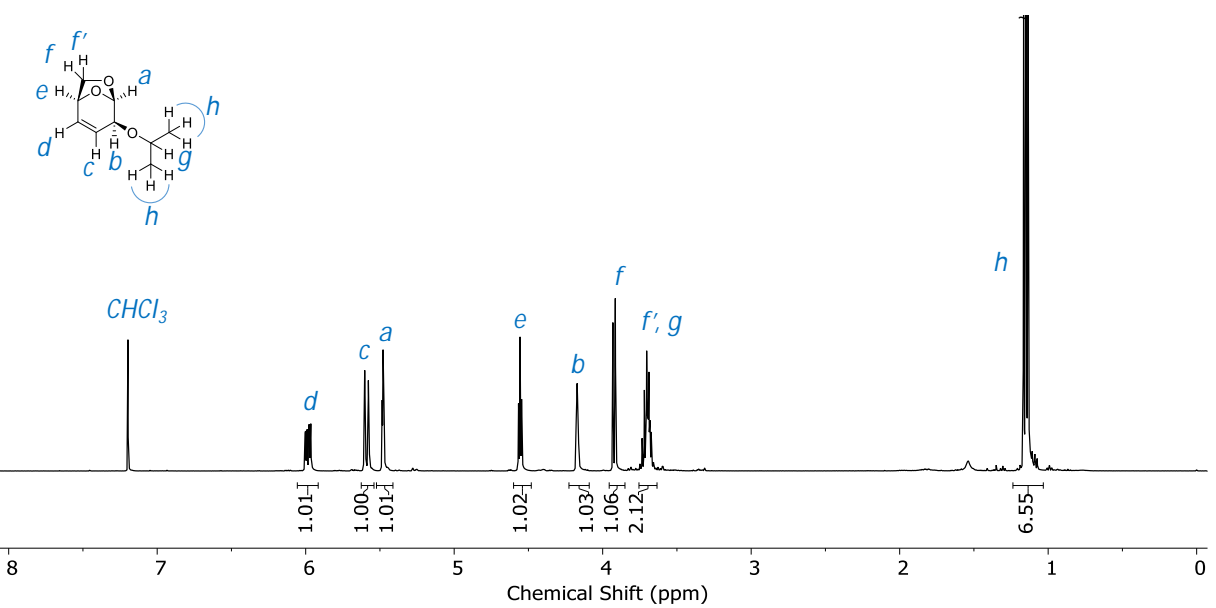

Figure S8. ${ }^{1} \mathrm{H}$ NMR (400 M Hz) spectrum of levoglucosenyl isopropyl ether $2 \mathbf{e}$ in $\mathrm{CDCl}_{3}$. 


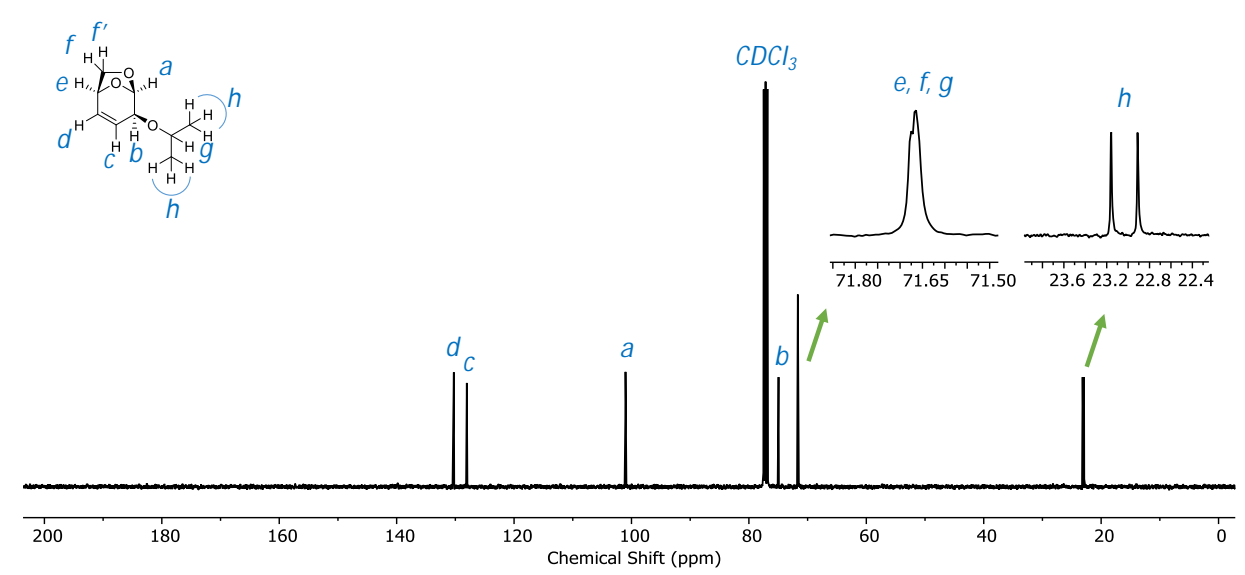

Figure S9. ${ }^{13} \mathrm{C}$ NM R (101 M Hz) spectrum of levoglucosenyl isopropyl ether $2 \mathbf{e}$ in $\mathrm{CDCl}_{3}$.

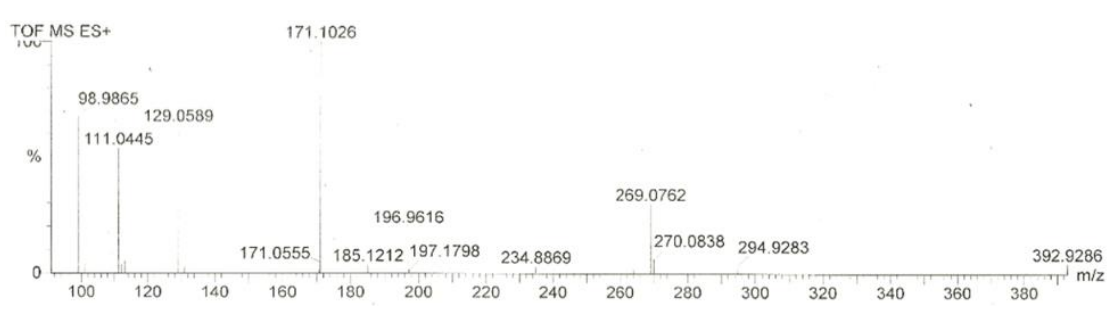

Figure S10. ESI-M S spectrum of levoglucosenyl isopropyl ether $\mathbf{2 e}$.

Levoglucosenyl $\mathrm{n}$-butyl ether $\mathbf{2 f}$. $1.5 \mathrm{~g}$ of $\mathrm{NaH}$ (60\% dispersion in mineral oil) was placed in a dry flask fitted with a septum and washed three times with dry cyclohexane. Dry THF (30 mL) was added and the mixture was cooled in an ice bath with constant stirring. A solution of levoglucosenol $(3.2 \mathrm{~g})$ in 30 $\mathrm{mL}$ of dry THF was added to the mixture and after the effervescence stopped, a solution of 1bromobutane ( $10.7 \mathrm{ml}, 4$ equiv) in $20 \mathrm{~mL}$ of dry THF and tetrabutylammonium iodide $(0.1 \mathrm{~g})$ were added. The mixture was stirred at room temperature until TLC showed complete consumption of the levoglucosenol. The crude mixture was poured into ice-cold water and extracted with DCM several times. The DCM portions were combined and evaporated in a rotary evaporator. The crude product was distilled in a Kugelrohr apparatus at $140{ }^{\circ} \mathrm{C}$ under reduced pressure $(0.1 \mathrm{mbar})$ to obtain levoglucosenyl n-butyl ether as colorless liquid $(3.3 \mathrm{~g})$, overall yield: $72 \%$. ${ }^{1} \mathrm{H} N \mathrm{NM}\left(400 \mathrm{M} \mathrm{Hz}, \mathrm{CDCl}_{3}\right) \delta$ 6.02 (ddd, J = 9.9, 4.2, $1.4 \mathrm{~Hz}, 1 \mathrm{H}), 5.65(\mathrm{dt}, \mathrm{J}=9.9,2.2 \mathrm{~Hz}, 1 \mathrm{H}), 5.55(\mathrm{t}, \mathrm{J}=2.3 \mathrm{~Hz}, 1 \mathrm{H}), 4.57$ (t, J = 4.1 $\mathrm{Hz}, 1 \mathrm{H}), 4.10(\mathrm{~s}, 0 \mathrm{H}), 3.91(\mathrm{~d}, \mathrm{~J}=6.6 \mathrm{~Hz}, 1 \mathrm{H}), 3.71(\mathrm{ddd}, \mathrm{J}=6.5,4.1,1.1 \mathrm{~Hz}, 1 \mathrm{H}), 3.57-3.47(\mathrm{~m}, 2 \mathrm{H}), 0.85$ $(\mathrm{t}, \mathrm{J}=7.4 \mathrm{~Hz}, 3 \mathrm{H}) .{ }^{13} \mathrm{CNMR}\left(101 \mathrm{M} \mathrm{Hz}, \mathrm{CDCl}_{3}\right) \delta 130.61,126.96,100.38,76.96,71.72,71.67,69.63,32.17$, 19.34, 14.02. ESI-M S [M -H] ${ }^{+} \mathrm{m} / \mathrm{z} 185.1169$ (calc. $\mathrm{C}_{10} \mathrm{H}_{16} \mathrm{O}_{3} 184.110 \mathrm{Da}$ ). 


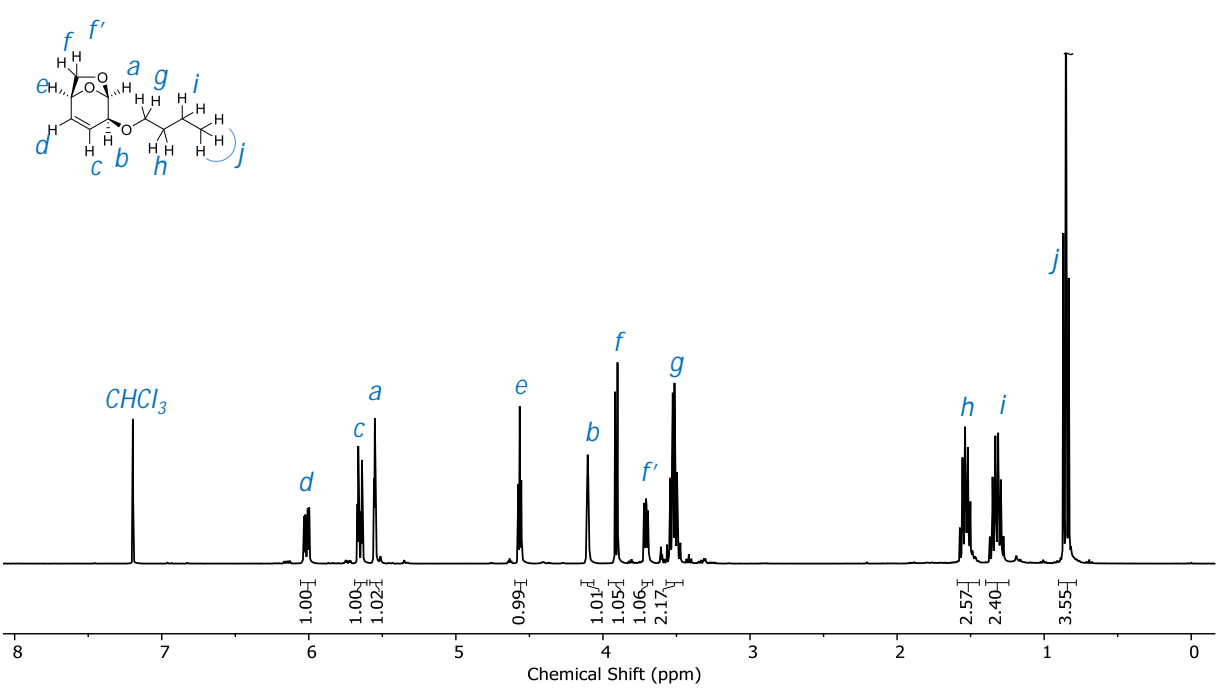

Figure S11. ${ }^{1} \mathrm{H}$ NM R (400 M Hz) spectrum of levoglucosenyl $n$-butyl ether $\mathbf{2} f$ in $\mathrm{CDCl}_{3}$.

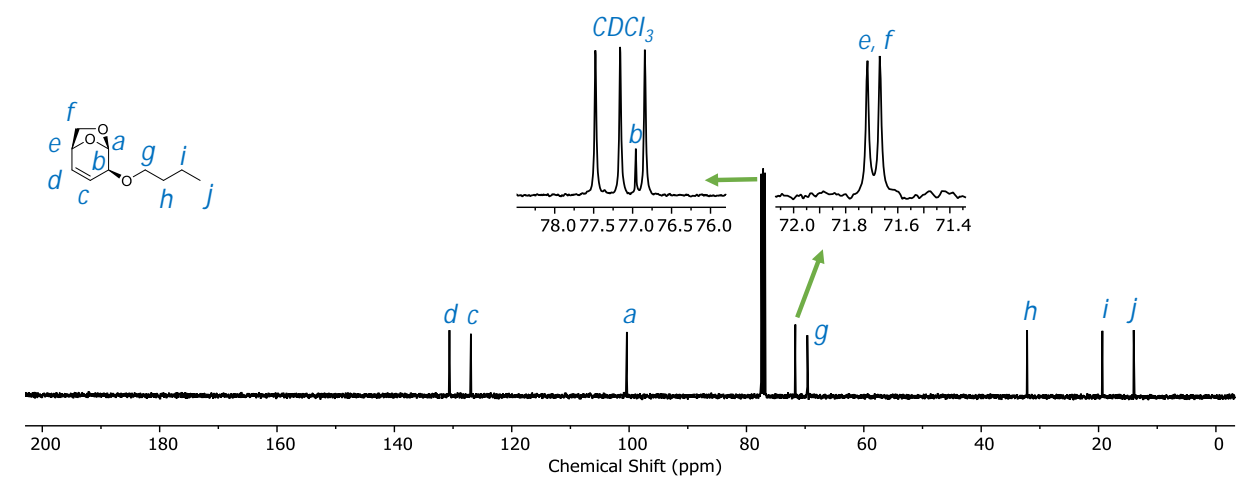

Figure S12. ${ }^{13} \mathrm{C}$ NM R (101 M Hz) spectrum of levoglucosenyl $n$-butyl ether $\mathbf{2 f}$ in $\mathrm{CDCl}_{3}$.

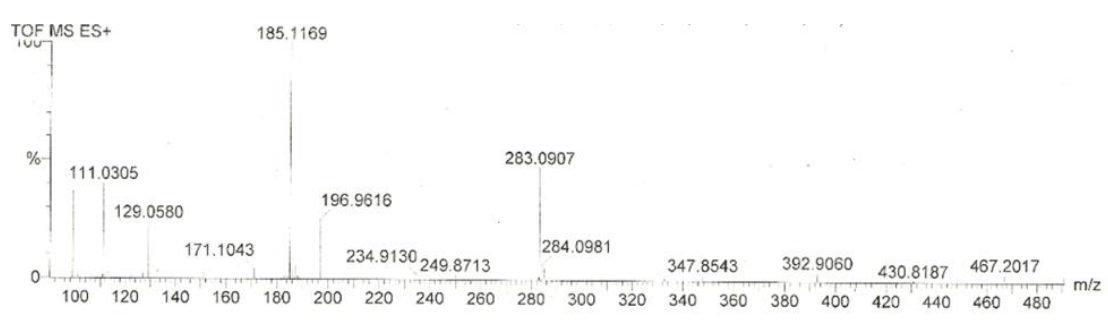

Figure S13. ESI-M S spectrum of levoglucosenyl n-butyl ether $\mathbf{2 f}$. 


\section{Polymerization procedures}

Polymerization of levoglucosenyl alkyl ethers $\mathbf{2 b}$-f in different solvents (1,4-dioxane, DCM, 2-M eTHF, Cyrene, and ethyl acetate) - exemplary procedure

Levoglucosenyl alkyl ether $\mathbf{2} \mathbf{b}-\mathbf{f}$ ( $4 \mathrm{mmol}$ ) was placed in a septum-sealed dry glass vial with magnetic stirring bar. Half of the required volume of solvent $(0.75 \mathrm{~mL}$ of 1,4-dioxane, DCM , 2-M eTHF, Cyrene, or ethyl acetate) was added to the vial with constant stirring under nitrogen. Then, the required amount of Grubbs catalyst C793 $(0.04 \mathrm{mmol})$ dissolved in the other half volume of solvent $(0.75 \mathrm{~mL})$ was added to the vial through a syringe. The timer was started at this time. Samples were taken out at defined time intervals through a syringe under nitrogen and quenched immediately by adding it to a solution of ethyl vinyl ether in DCM and stirring for $30 \mathrm{~min}$ at $30^{\circ} \mathrm{C}$. After the solvent was evaporated and a minimum amount of DCM was added, the polymer was precipitated into diethyl ether, centrifuged, and dried in vacuum at $40{ }^{\circ} \mathrm{C}$.

$\underline{\text { In situ kinetic study of polymerization of levoglucosenyl methyl ether } \mathbf{2 b} \text { in } 1,4 \text {-dioxane- } \mathrm{d}_{8}}$

Levoglucosenyl methyl ether $\mathbf{2} \mathbf{b}(0.5-2 \mathrm{mmol})$ was dissolved in $0.5 \mathrm{~mL}$ of 1,4-dioxane- $\mathrm{d}_{8}$ (+HM D) in a dry NMR tube. The Grubbs catalyst C793 (0.01-0.04 mmol) in powder form was then placed carefully inside at the tip of the NMR tube with a thin spatula. The NMR tube was capped and the joint was wrapped with parafilm while keeping the whole NM R tube inclined to keep the catalyst separated from the monomer solution. Just before loading to the sample holder, the NM R tube was vigorously shaken for 20-30 s to mix the reactants. The timer was started at this time and was adjusted with the first measurement. A series of measurements (8 or 16 scans) were carried out at different time intervals. At the end of the experiment, the sample was quenched with a solution of ethyl vinyl ether in DCM . 

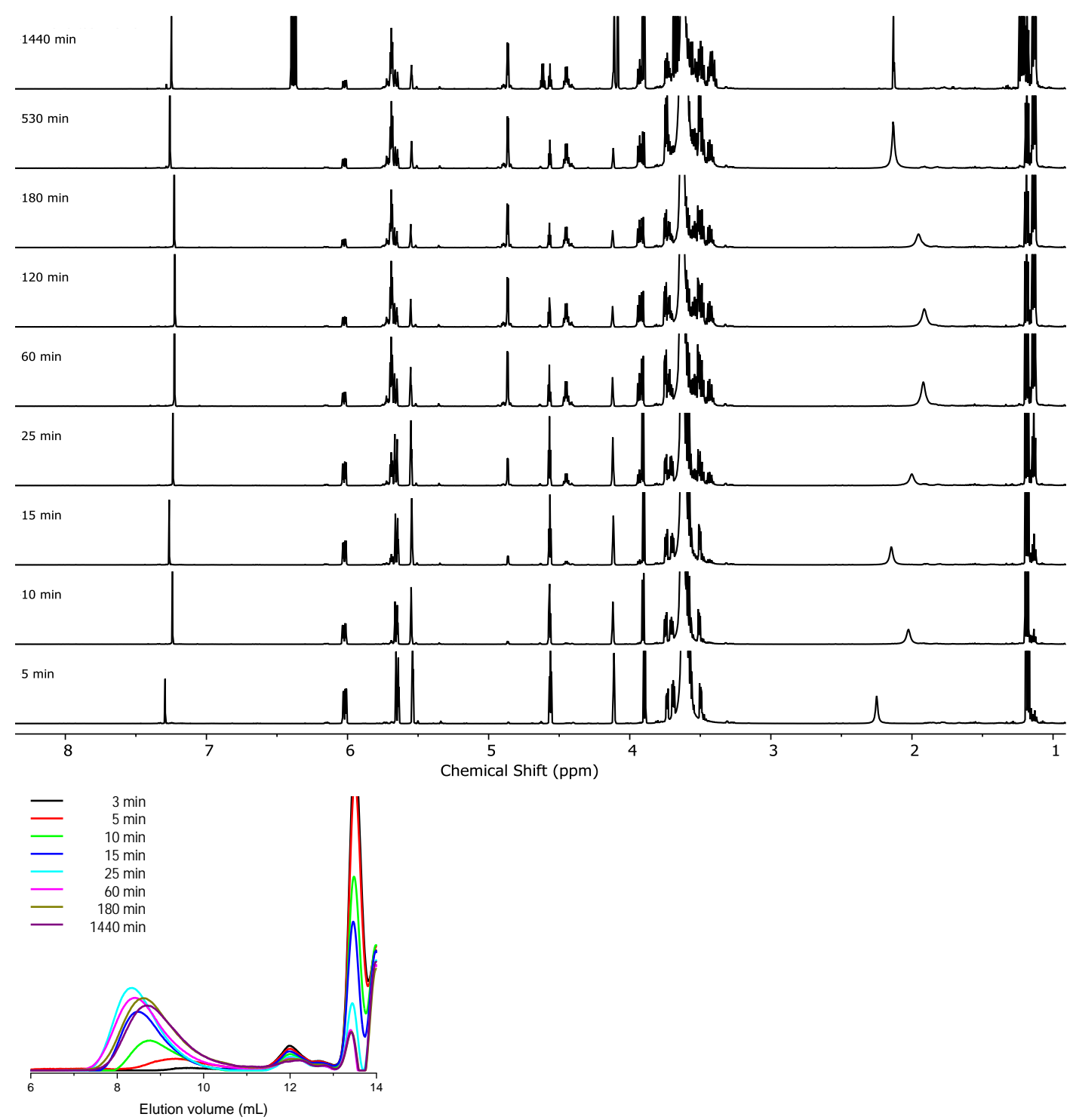

Figure S14. ${ }^{1} \mathrm{H}$ NM R (500 M Hz) spectra (top) and SEC-RI traces (bottom) of reaction mixtures taken during the polymerization of levoglucosenyl methyl ether $\mathbf{2} \mathbf{b}$ ( $4 \mathrm{mmol}$ ) with catalyst C793 (0.04 mmol) in 1,4-dioxane $(1 \mathrm{~mL})$ solution at room temperature. Samples were quenched with ethyl vinyl ether and diluted with $\mathrm{CDCl}_{3}$ (NM R) or THF (SEC).
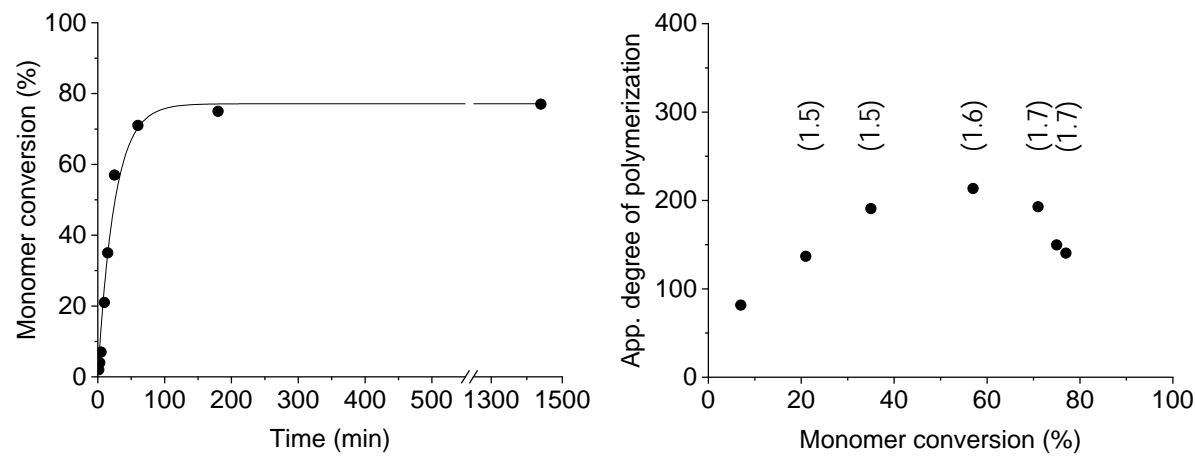

Figure S15. Polymerization of levoglucosenyl methyl ether $\mathbf{2 b}$ (4 mmol) with catalyst C793 (0.04 mmol) in 1,4-dioxane at room temperature: time-conversion plot (monomer conversions were determined by ${ }^{1} \mathrm{H}$ NMR analysis) (left) and evolution of the apparent number-average degree of polymerization and dispersity (as determined by SEC) as function of monomer conversion (right). 
Poly(levoglucosenyl methyl ether) $\mathbf{3 b}$ (purified sample produced at $1440 \mathrm{~min}$ )

${ }^{1} \mathrm{H}$ NMR $\left(500 \mathrm{M} \mathrm{Hz}, \mathrm{CD}_{2} \mathrm{Cl}_{2}\right) \delta 5.78-5.58(\mathrm{~m}, 1 \mathrm{H}), 4.90-4.80(\mathrm{~d}, \mathrm{~J}=3.9 \mathrm{~Hz}, 0 \mathrm{H}), 4.48-4.36(\mathrm{~m}, 1 \mathrm{H}), 3.98-$ $3.86(\mathrm{~m}, 1 \mathrm{H}), 3.65-3.55(\mathrm{~m}, 1 \mathrm{H}), 3.50-3.40(\mathrm{~m}, 1 \mathrm{H}), 3.27(\mathrm{~s}, 3 \mathrm{H}) .{ }^{13} \mathrm{C} \mathrm{NMR}\left(126 \mathrm{M} \mathrm{Hz}, \mathrm{CD}_{2} \mathrm{Cl}_{2}\right) \delta 132.47$, $130.30,105.70,82.91,77.75,70.63,57.84$.
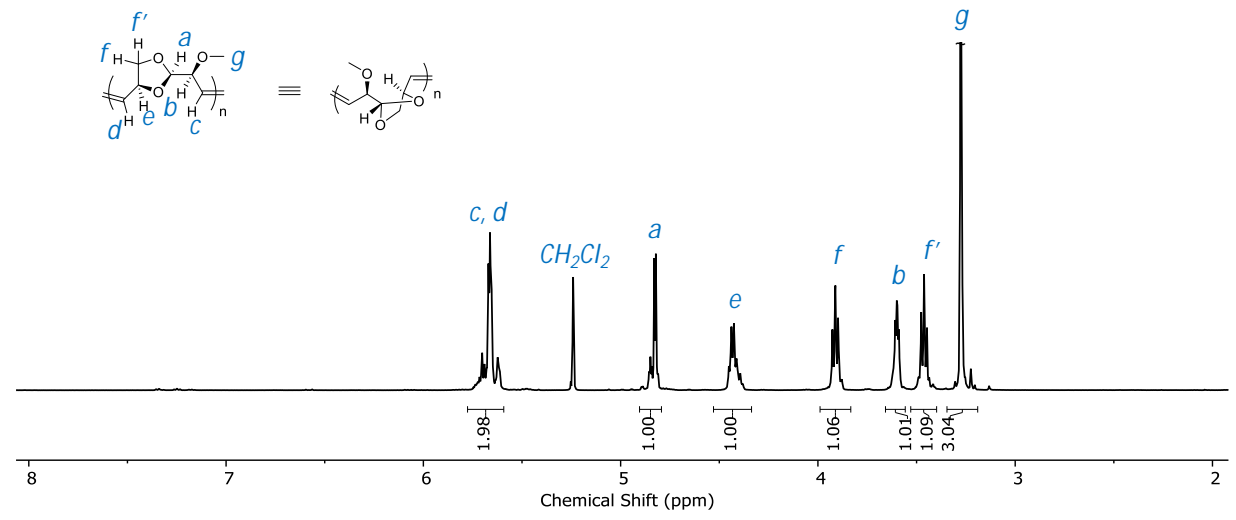

Figure S16. ${ }^{1} \mathrm{H}$ NM R (500 M Hz) spectrum of poly(levoglucosenyl methyl ether) $3 \mathbf{b}$ in $\mathrm{CD}_{2} \mathrm{Cl}_{2}$.

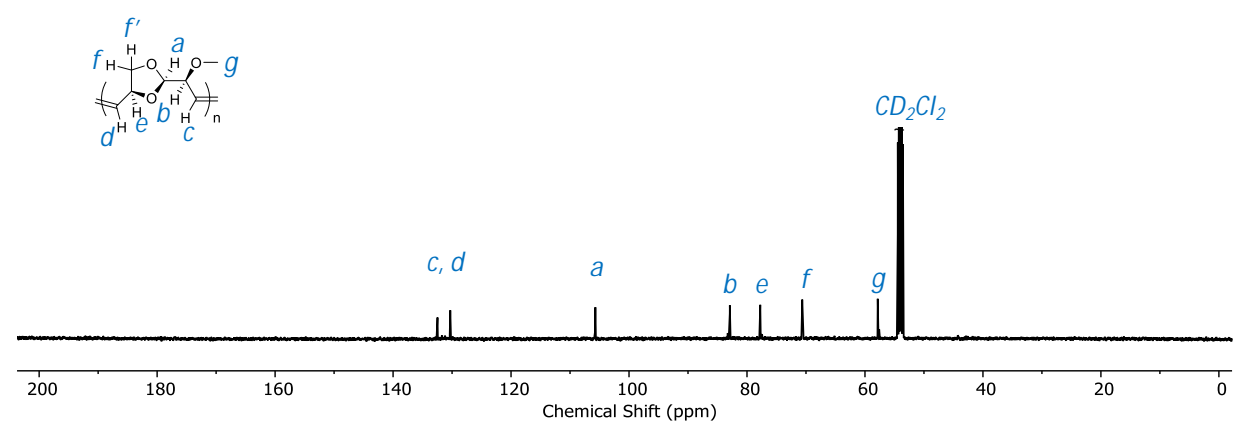

Figure S17. ${ }^{13} \mathrm{C}$ NM R (126 M Hz) spectrum of poly(levoglucosenyl methyl ether) $3 \mathbf{b}$ in $\mathrm{CD}_{2} \mathrm{Cl}_{2}$.

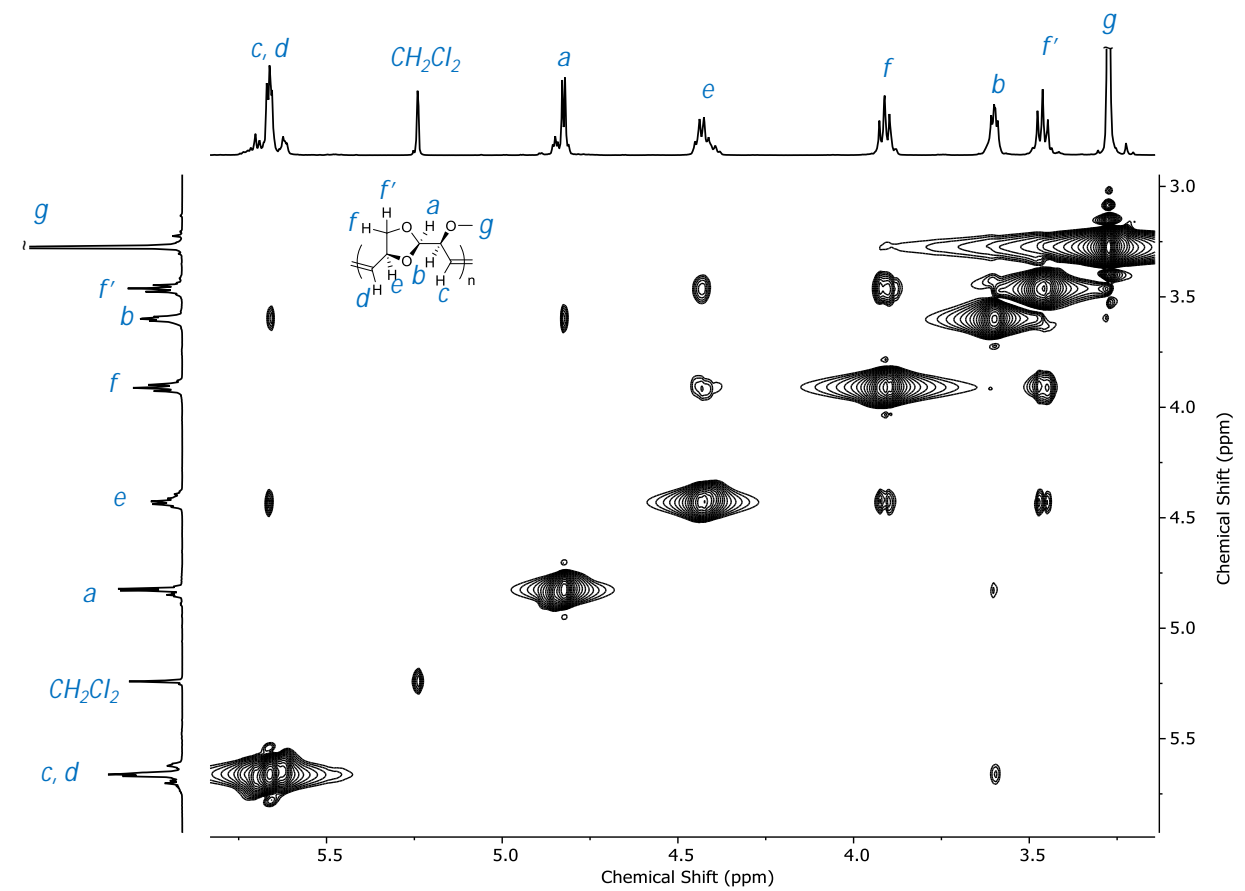

Figure S18. ${ }^{1} \mathrm{H}-{ }^{1} \mathrm{H}$ COSY NM R (500M Hz) spectrum of poly(levoglucosenyl methyl ether) $3 \mathbf{b}$ in DM SO- $\mathrm{d}_{6}$. 


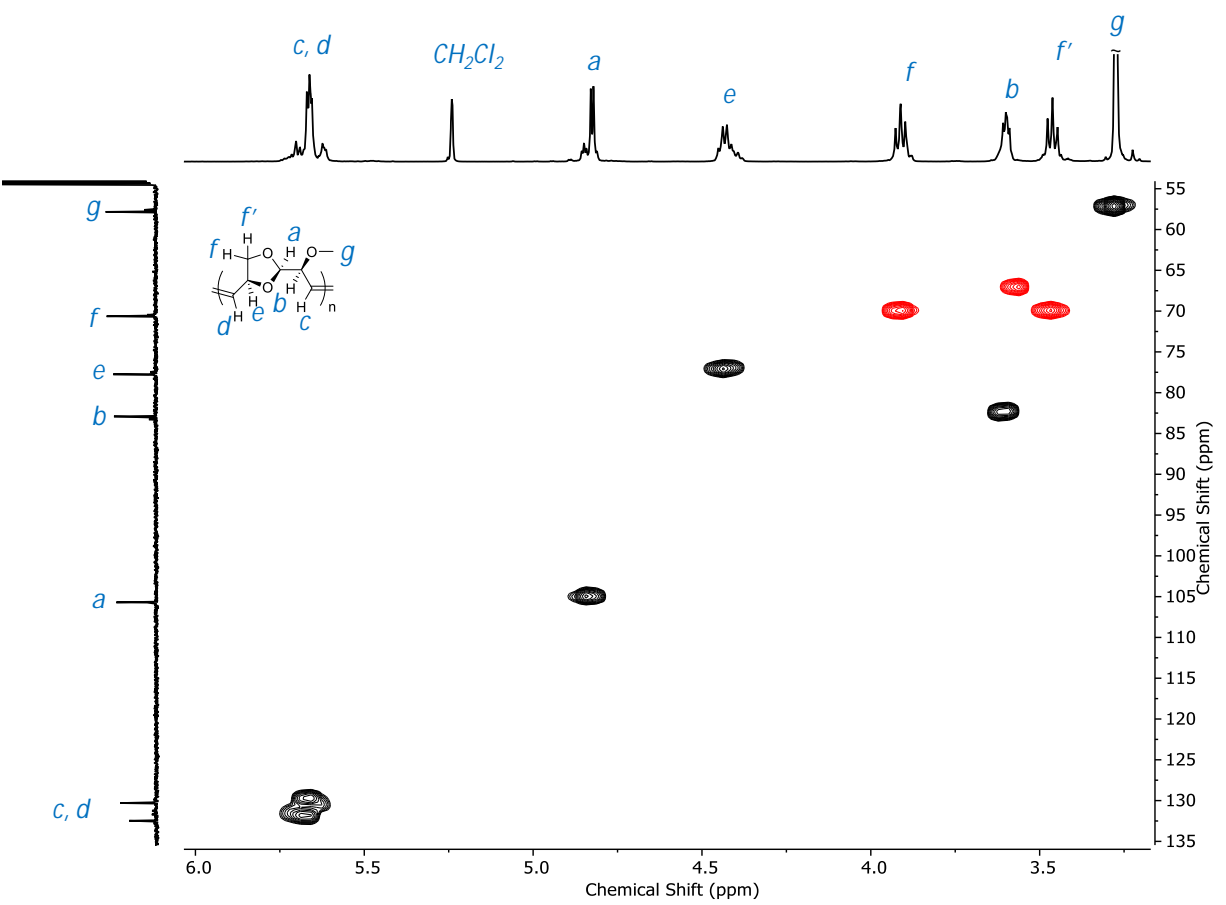

Figure S19. ${ }^{1} \mathrm{H}-{ }^{13} \mathrm{C} \mathrm{HSQC} \mathrm{NM} \mathrm{R} \mathrm{(500M} \mathrm{Hz)} \mathrm{spectrum} \mathrm{of} \mathrm{poly(levoglucosenyl} \mathrm{methyl} \mathrm{ether)} 3 \mathbf{b}$ in DM SO-d $\mathrm{d}_{6}$.
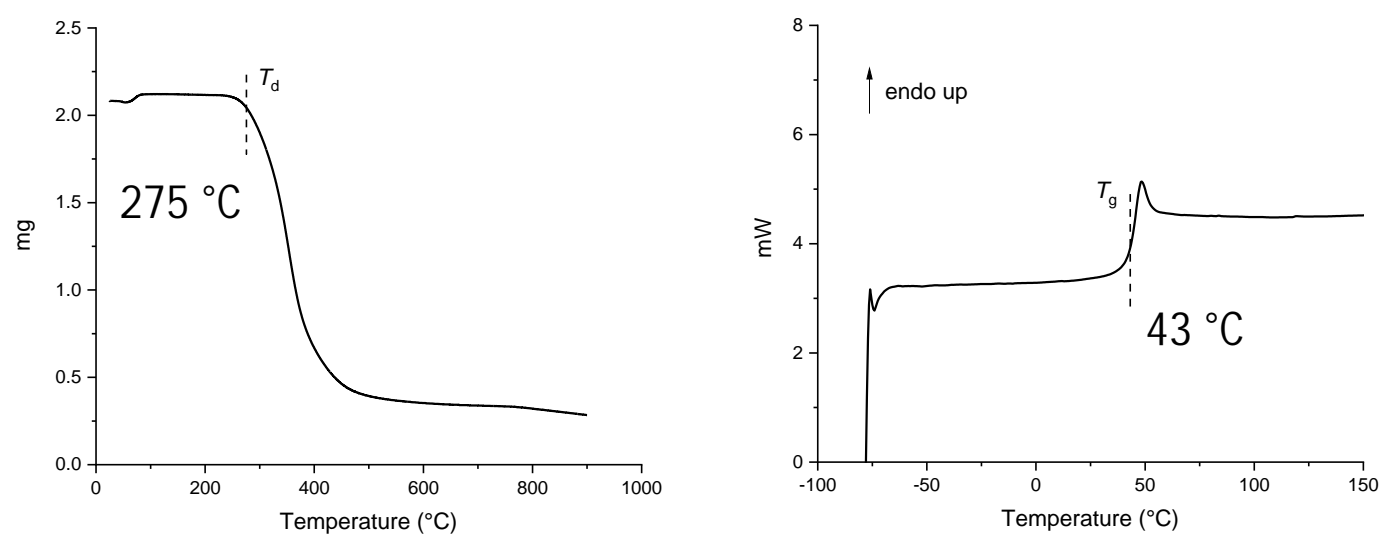

Figure S20. TGA curve (left) and DSC third heating curve (right) of poly(levoglucosenyl methyl ether) $3 b$. 

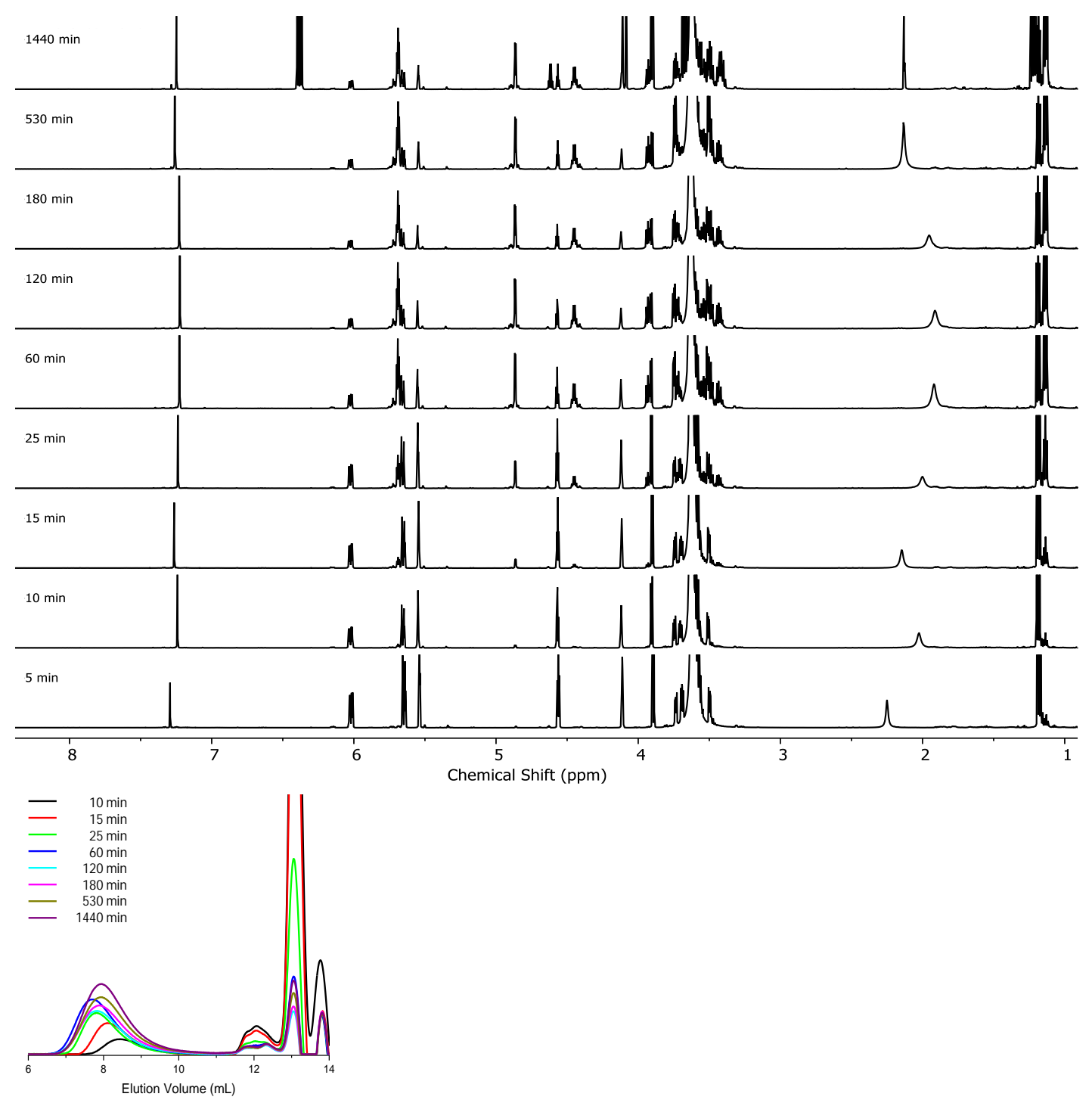

Figure S21. ${ }^{1} \mathrm{H}$ NM R (500 M Hz) spectra (top) and SEC-RI traces (bottom) of reaction mixtures taken during the polymerization of levoglucosenyl ethyl ether $\mathbf{2 c}(4 \mathrm{mmol})$ with catalyst $\mathrm{C} 793(0.04 \mathrm{mmol})$ in 1,4-dioxane $(1 \mathrm{~mL})$ solution at room temperature. Samples were quenched with ethyl vinyl ether and diluted with $\mathrm{CDCl}_{3}$ (NM R) or THF (SEC).
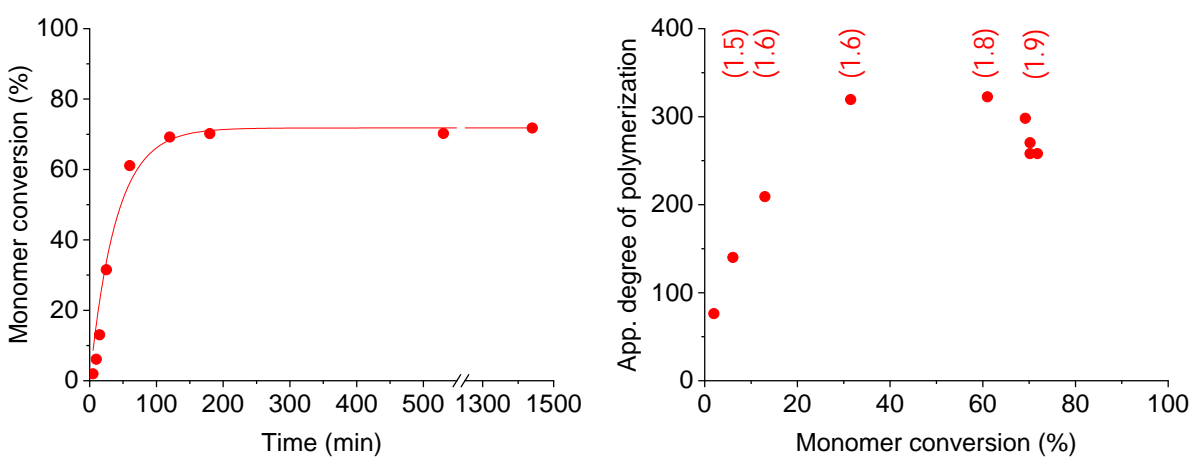

Figure S22. Polymerization of levoglucosenyl ethyl ether $\mathbf{2 c}$ ( $4 \mathrm{mmol}$ ) with catalyst C793 (0.04 mmol) in 1,4-dioxane at room temperature: time-conversion plot (monomer conversions were determined by ${ }^{1} \mathrm{H}$ NMR analysis) (left) and evolution of the apparent number-average degree of polymerization and dispersity (as determined by SEC) as function of monomer conversion (right). 
Poly(levoglucosenyl ethyl ether) $\mathbf{3 c}$ (purified sample produced at $1440 \mathrm{~min}$ )

${ }^{1} \mathrm{H} \mathrm{NM} \mathrm{R}\left(500 \mathrm{M} \mathrm{Hz}, \mathrm{CDCl}_{3}\right) \delta 5.82-5.59(\mathrm{~m}, 1 \mathrm{H}), 4.95-4.77(\mathrm{~m}, 1 \mathrm{H}), 4.55-4.34(\mathrm{~m}, 1 \mathrm{H}), 4.02-3.84(\mathrm{~m}, \mathrm{OH})$, 3.81-3.70 (m, 1H), 3.59-3.52 (m, 1H), 3.52-3.46 (m, 1H), 3.47-3.38 (m, $1 \mathrm{H}) .{ }^{13} \mathrm{C} \mathrm{NM} \mathrm{R}\left(126 \mathrm{M} \mathrm{Hz}, \mathrm{CDCl}_{3}\right)$ $\delta 131.54,130.47,105.16,80.68,77.46,70.20,65.27,15.44$.

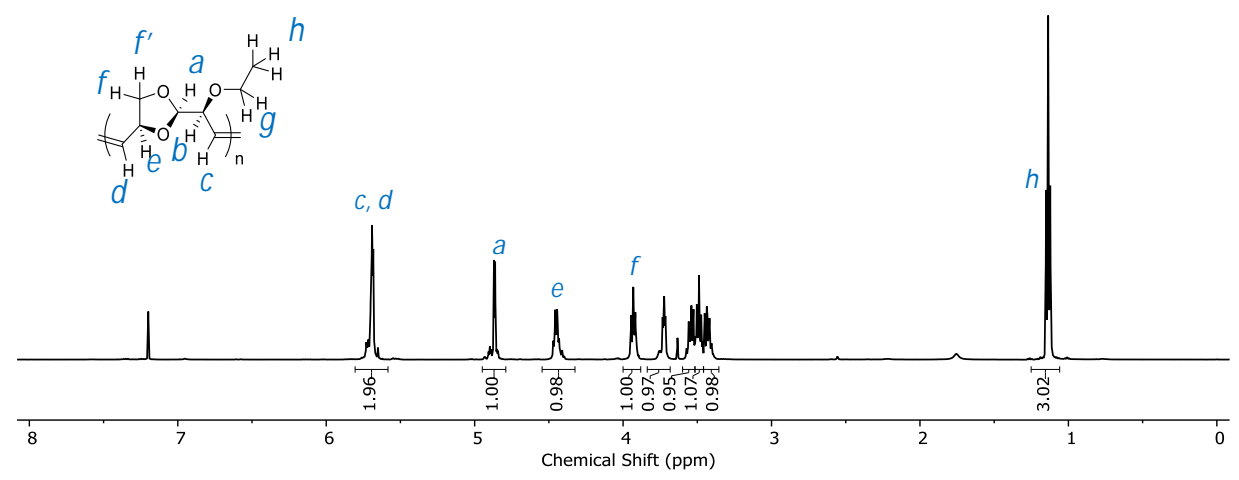

Figure S23. ${ }^{1} \mathrm{H} \mathrm{NM} \mathrm{R} \mathrm{(500} \mathrm{M} \mathrm{Hz)} \mathrm{spectrum} \mathrm{of} \mathrm{poly(levoglucosenyl} \mathrm{ethyl} \mathrm{ether)} 3 \mathrm{c}$ in $\mathrm{CDCl}_{3}$.

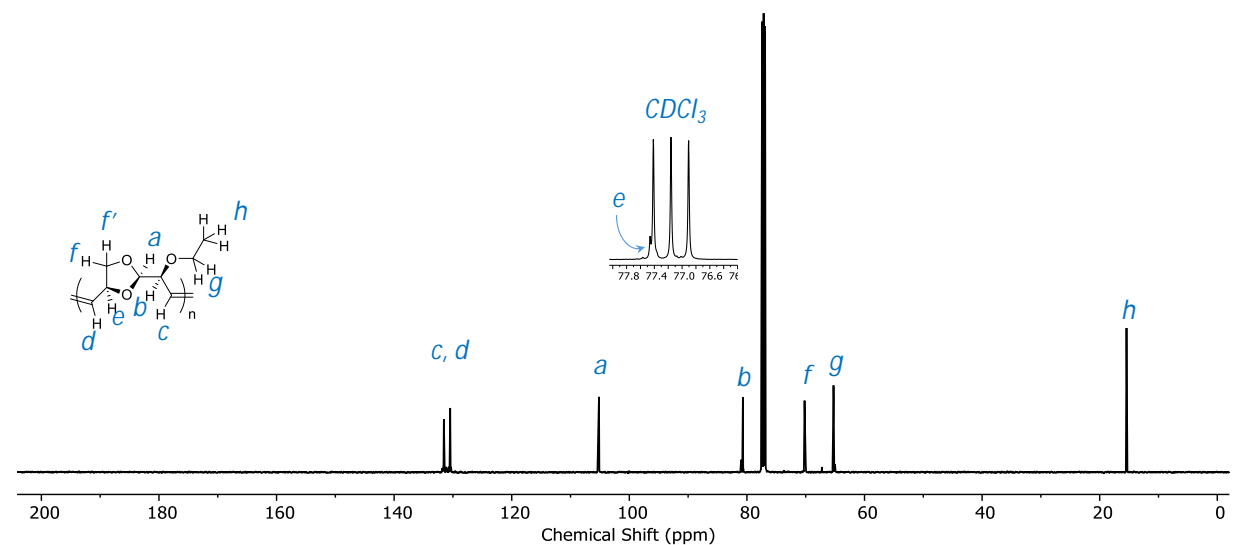

Figure $\mathrm{S} 24 .{ }^{13} \mathrm{C} \mathrm{NM} \mathrm{R}$ (126 M Hz) spectrum of poly(levoglucosenyl ethyl ether) $\mathbf{3 c}$ in $\mathrm{CDCl}_{3}$.

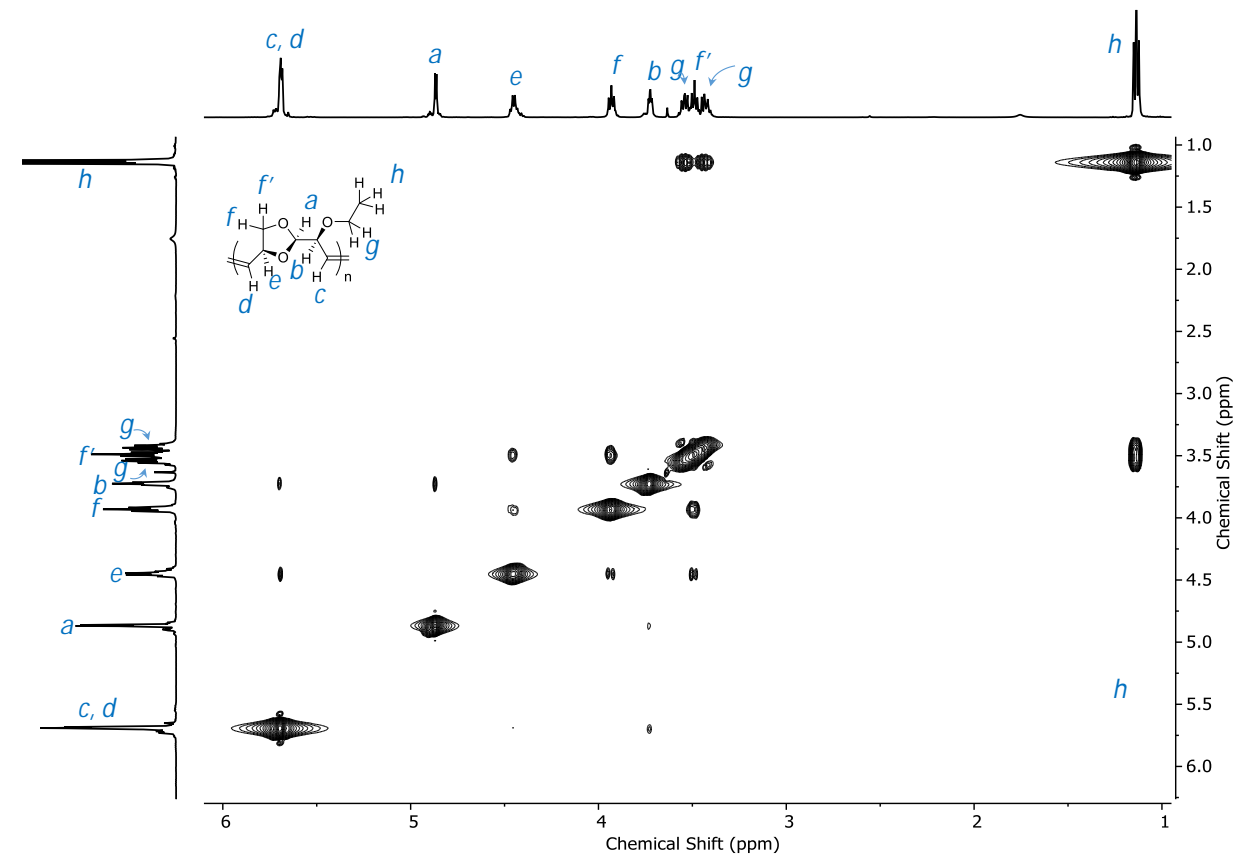

Figure S25. ${ }^{1} \mathrm{H}-{ }^{-1} \mathrm{H}$ COSY NM R $(500 \mathrm{M} \mathrm{Hz})$ spectrum of poly(levoglucosenyl ethyl ether) $3 \mathrm{c}$ in DM SO-d6. 


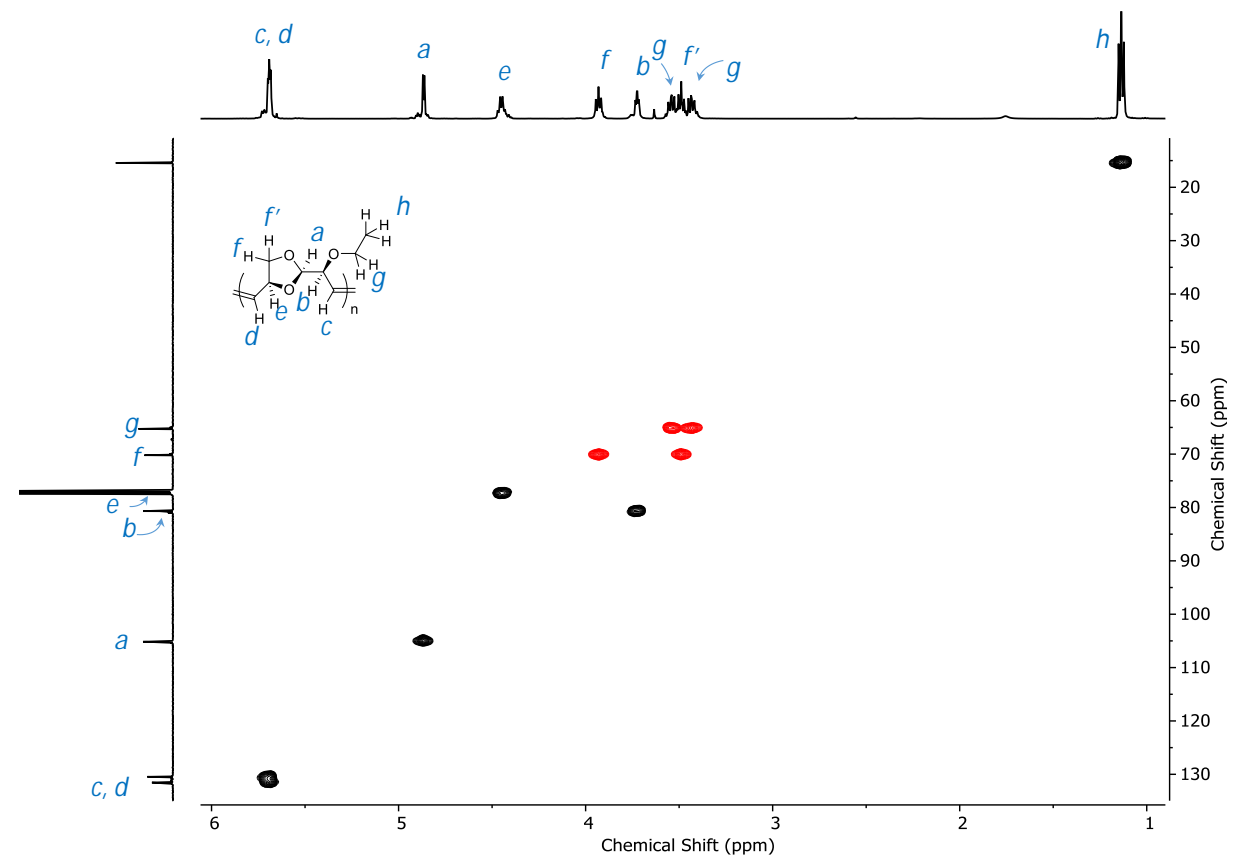

Figure S26. ${ }^{1} \mathrm{H}-{ }^{13} \mathrm{C} \mathrm{HSQC} \mathrm{NM} \mathrm{R} \mathrm{(500M} \mathrm{Hz)} \mathrm{spectrum} \mathrm{of} \mathrm{poly(levoglucosenyl} \mathrm{ethyl} \mathrm{ether)} 3 \mathbf{c}$ in DM SO- $\mathrm{d}_{6}$.
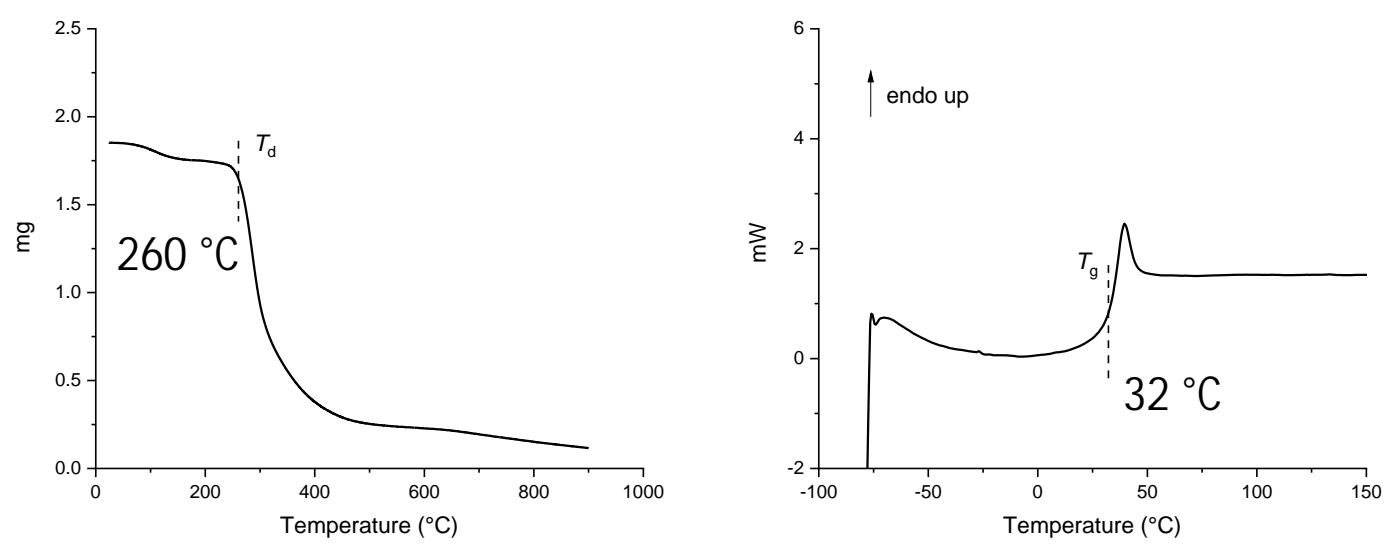

Figure S27. TGA curve (left) and DSC third heating curve (right) of poly(levoglucosenyl ethyl ether) 3c. 
Polymerization of levoglucosenyl n-propyl ether $\mathbf{2 d}$ in 1,4-dioxane

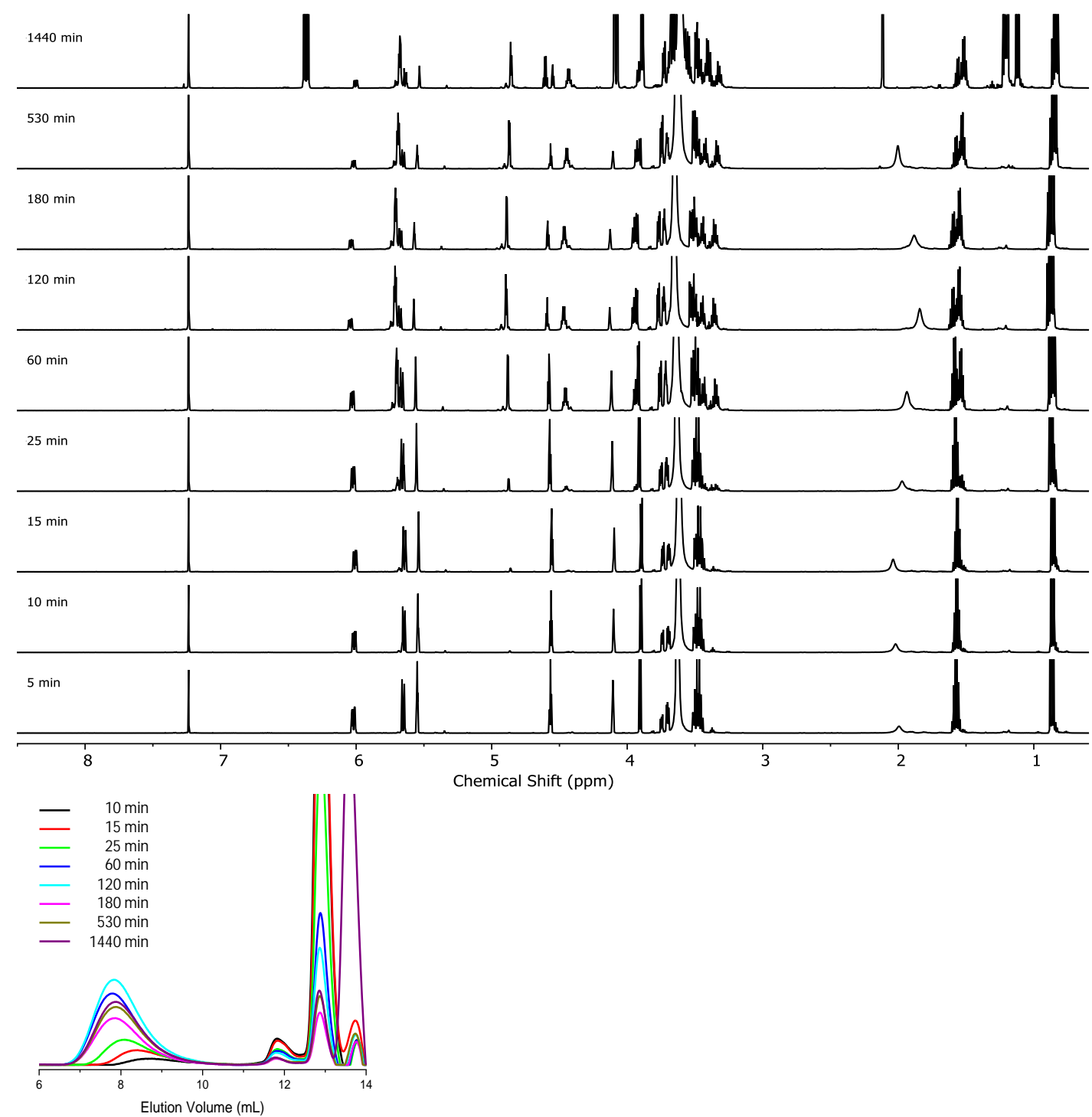

Figure S28. ${ }^{1} \mathrm{H}$ NM R (500 M Hz) spectra (top) and SEC-RI traces (bottom) of reaction mixtures taken during the polymerization of levoglucosenyl n-propyl ether $\mathbf{2} \mathbf{d}(3 \mathrm{mmol})$ with catalyst $\mathrm{C} 793$ ( $0.03 \mathrm{mmol})$ in 1,4-dioxane $(0.75 \mathrm{~mL})$ solution at room temperature. Samples were quenched with ethyl vinyl ether and diluted with $\mathrm{CDCl}_{3}$ (NM R) or THF (SEC).
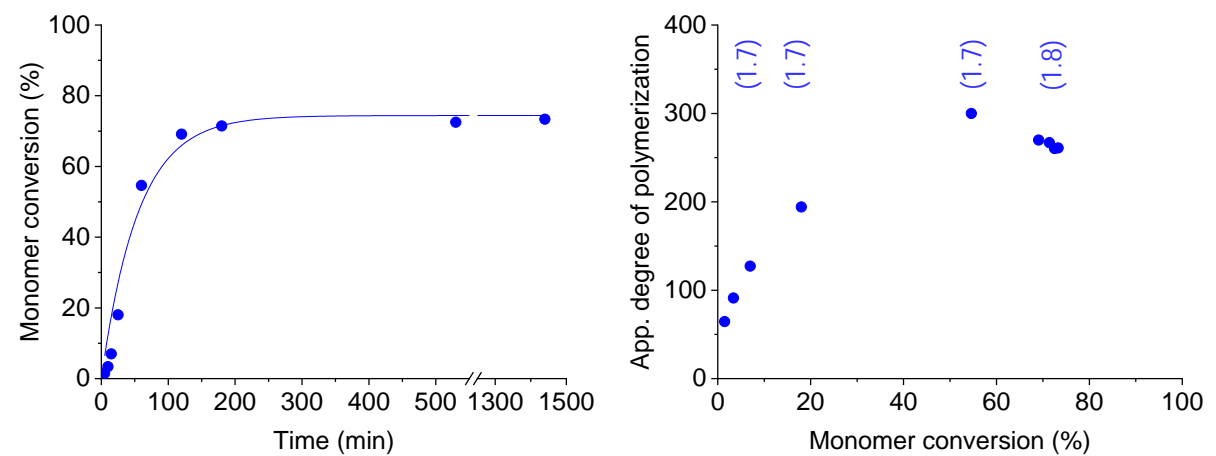

Figure S29. Polymerization of levoglucosenyl n-propyl ether $\mathbf{2 d}$ (3 mmol) with catalyst C793 (0.03 $\mathrm{mmol}$ ) in 1,4-dioxane at room temperature: time-conversion plot (monomer conversions were determined by ${ }^{1} \mathrm{H}$ NMR analysis) (left) and evolution of the apparent number-average degree of polymerization and dispersity (as determined by SEC) as function of monomer conversion (right). 
Poly(levoglucosenyl n-propyl ether) 3d (purified sample produced at $1440 \mathrm{~min}$ )

${ }^{1} \mathrm{H} \mathrm{NM} \mathrm{R}\left(500 \mathrm{M} \mathrm{Hz}, \mathrm{CDCl}_{3}\right) \delta 5.81-5.60(\mathrm{~m}, 2 \mathrm{H}), 4.96-4.80(\mathrm{~m}, 1 \mathrm{H}), 4.50-4.37(\mathrm{~m}, 1 \mathrm{H}), 3.97-3.89(\mathrm{~m}, 1 \mathrm{H})$, 3.75-3.73 (m, 1H), 3.52-3.46 (m, 1H), 3.47-3.39 (m, 1H), 3.38-3.30 (m, 1H), $1.53(\mathrm{q}, \mathrm{J}=7.1 \mathrm{~Hz}, 2 \mathrm{H}), 0.84$ $(\mathrm{t}, \mathrm{J}=7.4 \mathrm{~Hz}, 3 \mathrm{H}) .{ }^{13} \mathrm{CNMR}\left(126 \mathrm{M} \mathrm{Hz}, \mathrm{CDCl}_{3}\right) \delta 131.45,130.60,105.27,80.87,77.52,71.70,70.22,67.24$, $23.14,10.73$.

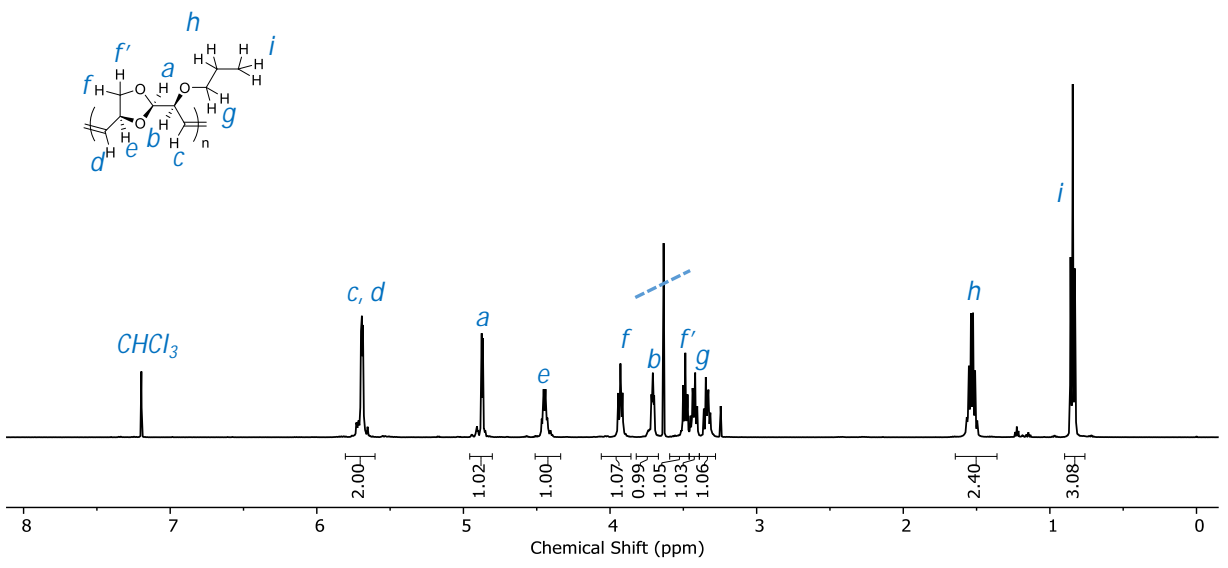

Figure S30. ${ }^{1} \mathrm{H}$ NMR (500 M Hz) spectrum of poly(levoglucosenyl n-propyl ether) $\mathbf{3 d}$ in $\mathrm{CDCl}_{3}$.

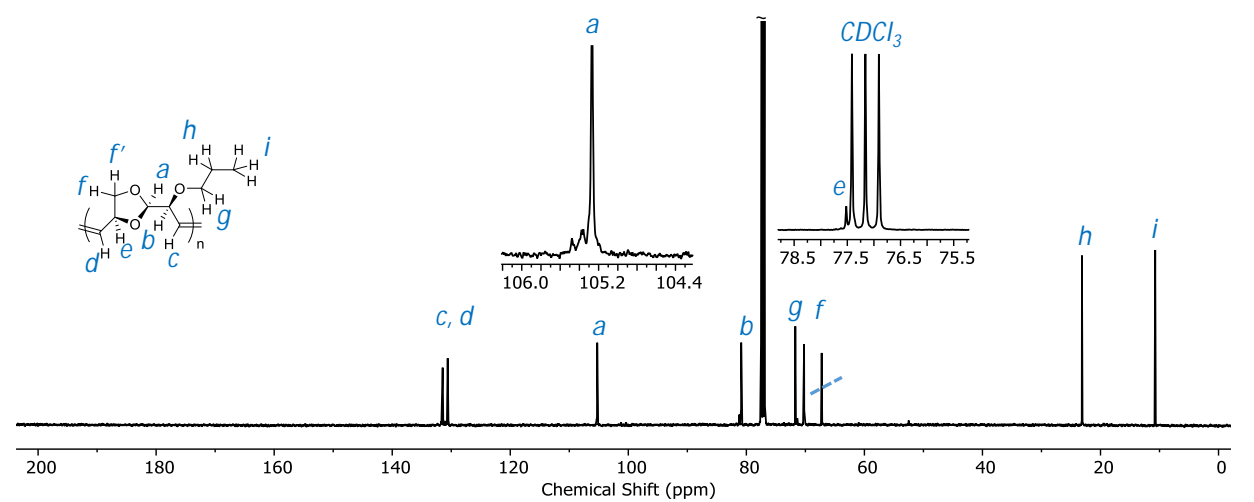

Figure S31. ${ }^{13} \mathrm{C}$ NM R (126 M Hz) spectrum of poly(levoglucosenyl n-propyl ether) $\mathbf{3 d}$ in $\mathrm{CDCl}_{3}$.

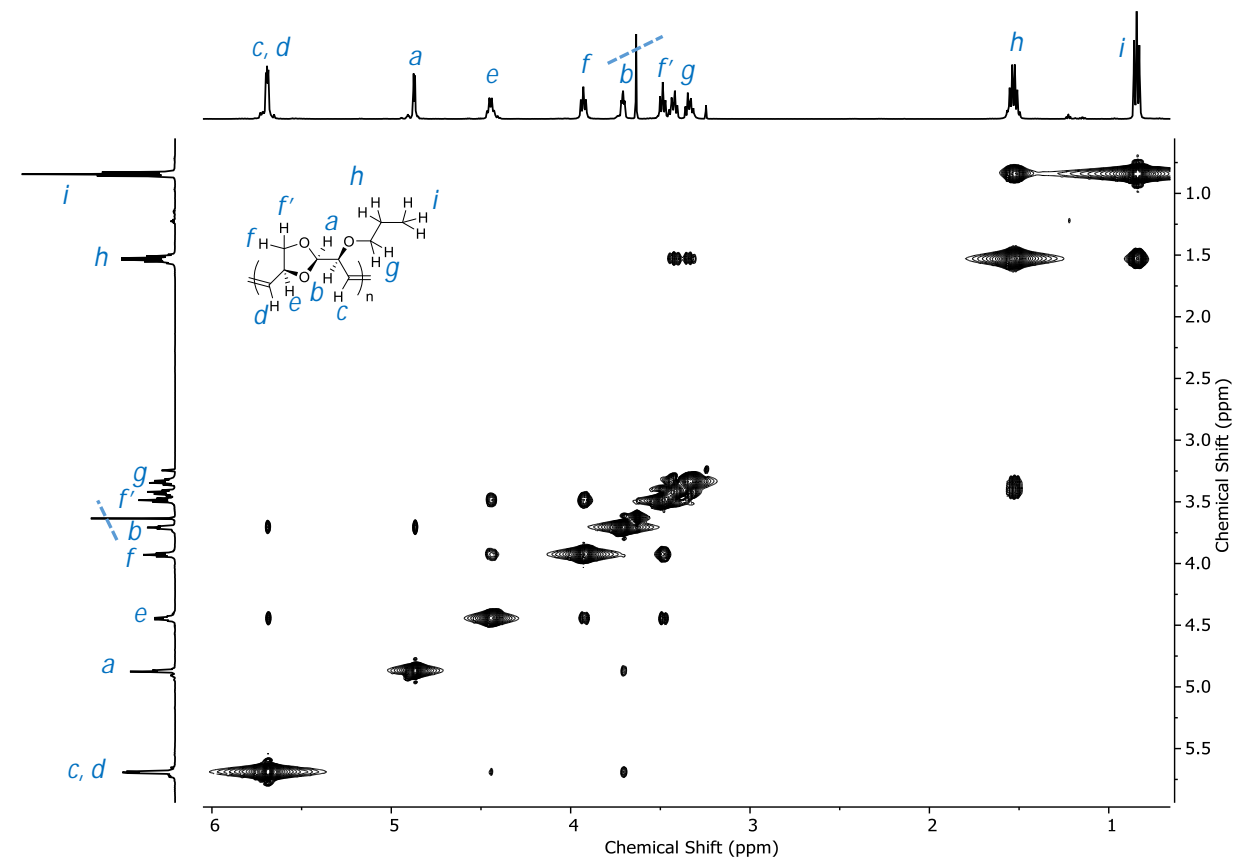

Figure S32. ${ }^{1} \mathrm{H}-{ }^{1} \mathrm{H}$ COSY NM R (500M Hz) spectrum of poly(levoglucosenyl n-propyl ether) $3 \mathbf{d}$ in DM SO-d $\mathrm{d}_{6}$. 


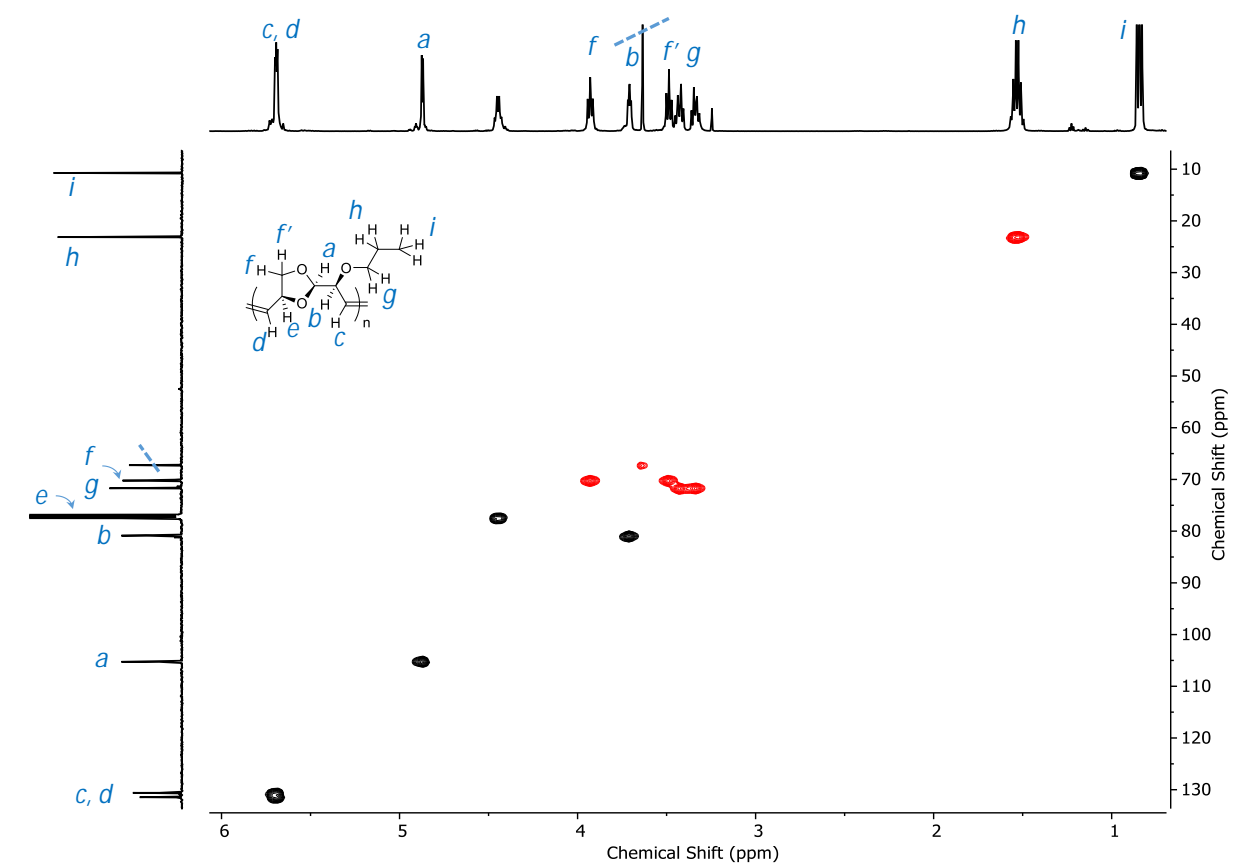

Figure S33. ${ }^{1} \mathrm{H}-{ }^{13} \mathrm{C} \mathrm{HSQC} \mathrm{NM} \mathrm{R} \mathrm{(500M} \mathrm{Hz)} \mathrm{spectrum} \mathrm{of} \mathrm{poly(levoglucosenyl} \mathrm{n-propyl} \mathrm{ether)} \mathbf{3} \mathbf{d}$ in DM SO-d 6 .
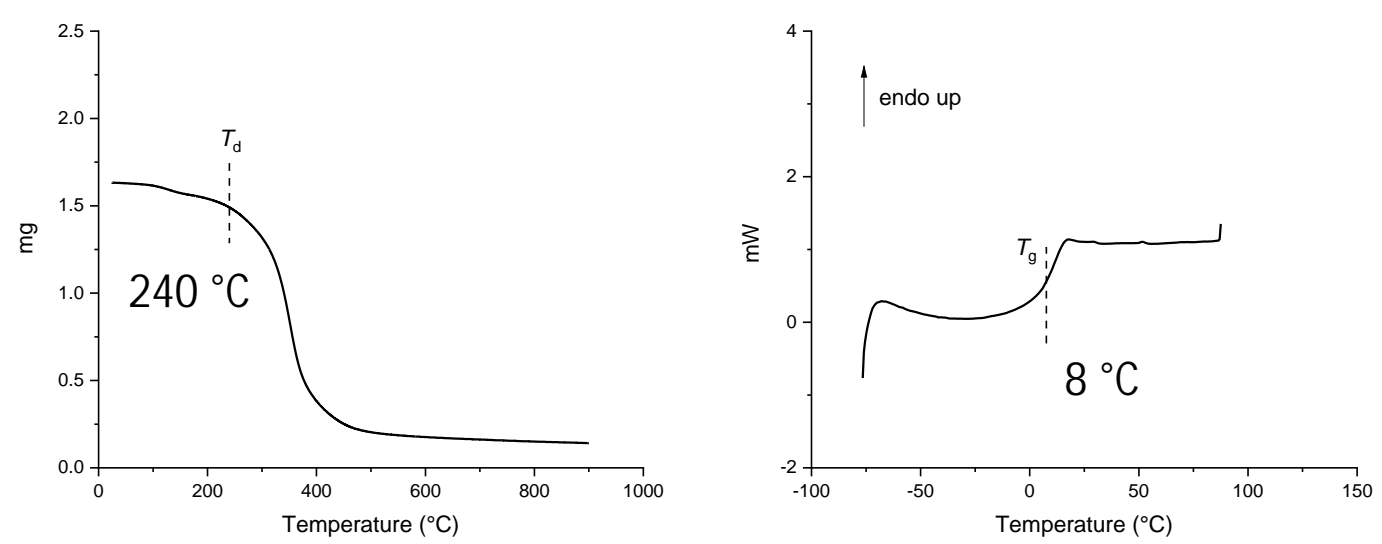

Figure S34. TGA curve (left) and DSC third heating curve (right) of poly(levoglucosenyl n-propyl ether) 3d. 

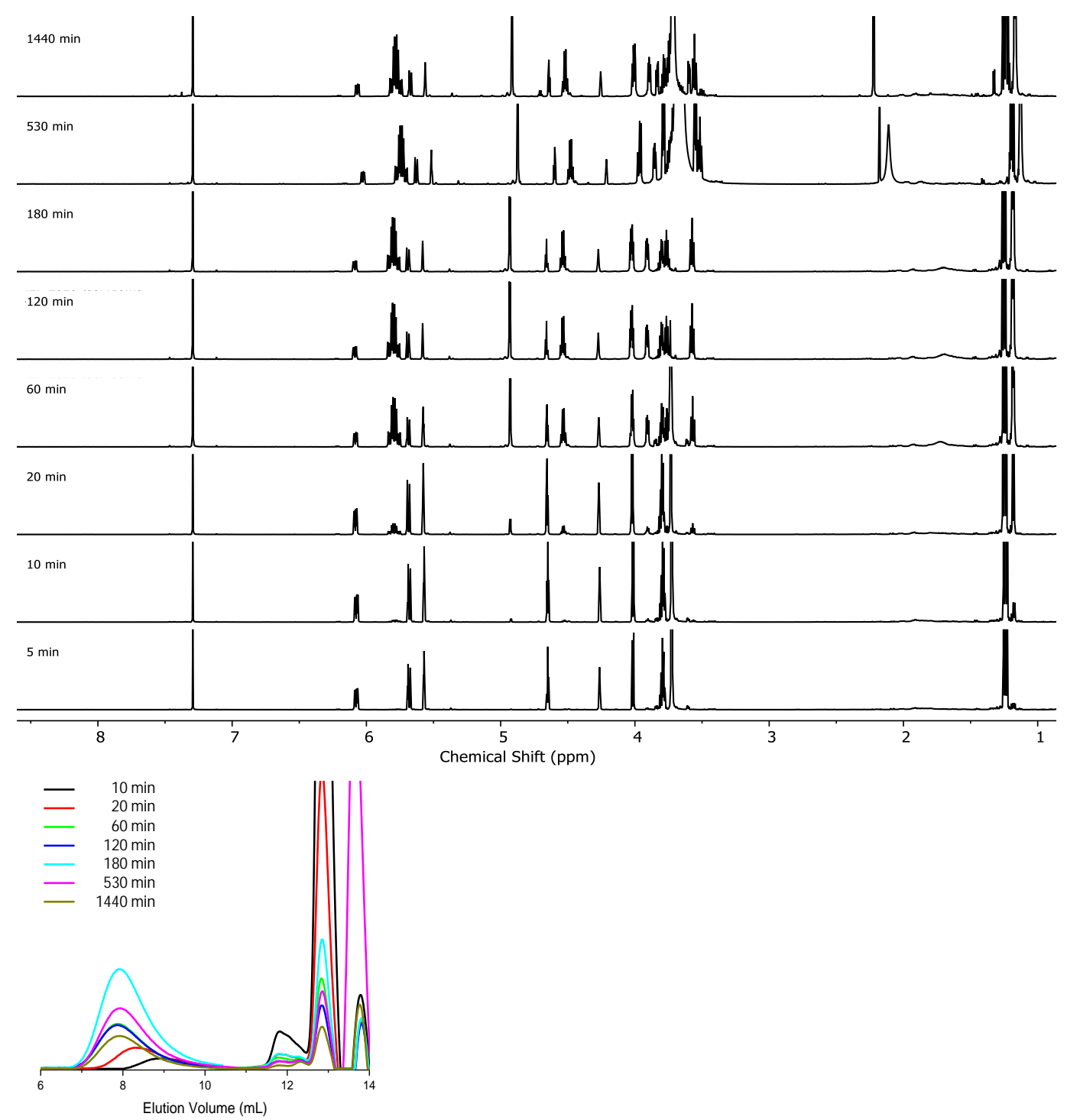

Figure S35. ${ }^{1} \mathrm{H}$ NMR (500 M Hz) spectra (top) and SEC-RI traces (bottom) of reaction mixtures taken during the polymerization of levoglucosenyl isopropyl ether $\mathbf{2 e}(3 \mathrm{mmol})$ with catalyst $\mathrm{C} 793(0.03$ $\mathrm{mmol})$ in 1,4-dioxane $(0.75 \mathrm{~mL})$ solution at room temperature. Samples were quenched with ethyl vinyl ether and diluted with $\mathrm{CDCl}_{3}$ (NM R) or THF (SEC).
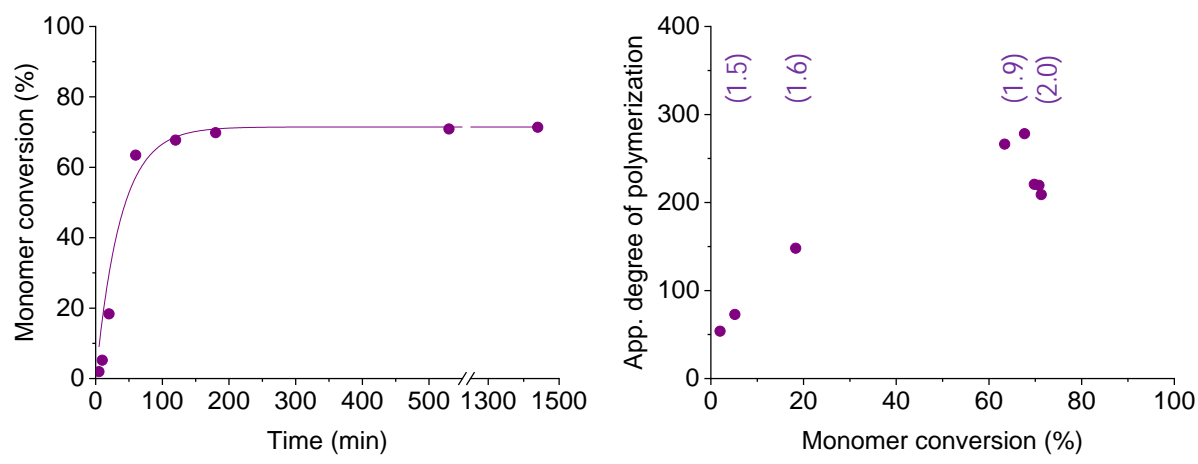

Figure S36. Polymerization of levoglucosenyl isopropyl ether $\mathbf{2 e}(3 \mathrm{mmol})$ with catalyst $\mathrm{C793}$ (0.03 $\mathrm{mmol}$ ) in 1,4-dioxane at room temperature: time-conversion plot (monomer conversions were determined by ${ }^{1} \mathrm{H}$ NMR analysis) (left) and evolution of the apparent number-average degree of polymerization and dispersity (as determined by SEC) as function of monomer conversion (right). 
$\underline{\text { Poly(levoglucosenyl isopropyl ether) 3e (purified sample produced at } 1440 \mathrm{~min} \text { ) }}$

${ }^{1} \mathrm{H} N M R\left(500 \mathrm{M} \mathrm{Hz}, \mathrm{CDCl}_{3}\right) \delta 5.70(\mathrm{dd}, \mathrm{J}=11.3,6.2 \mathrm{~Hz}, 1 \mathrm{H}), 4.83(\mathrm{~d}, \mathrm{~J}=3.9 \mathrm{~Hz}, 1 \mathrm{H}), 4.44(\mathrm{~d}, \mathrm{~J}=6.8 \mathrm{~Hz}$, $0 \mathrm{H}), 3.92(\mathrm{t}, \mathrm{J}=7.1 \mathrm{~Hz}, 1 \mathrm{H}), 3.81(\mathrm{dd}, \mathrm{J}=5.6,4.1 \mathrm{~Hz}, 1 \mathrm{H}), 3.67(\mathrm{p}, \mathrm{J}=6.1 \mathrm{~Hz}, 1 \mathrm{H}), 3.47(\mathrm{t}, \mathrm{J}=7.5 \mathrm{~Hz}, 1 \mathrm{H})$, $1.09(\mathrm{~d}, \mathrm{~J}=6.1 \mathrm{~Hz}, 4 \mathrm{H}) .{ }^{13} \mathrm{CNM} \mathrm{R}\left(126 \mathrm{M} \mathrm{Hz}, \mathrm{CDCl}_{3}\right) \delta 130.26,128.05,101.02,74.95,71.68,71.66,23.16$, 22.91.
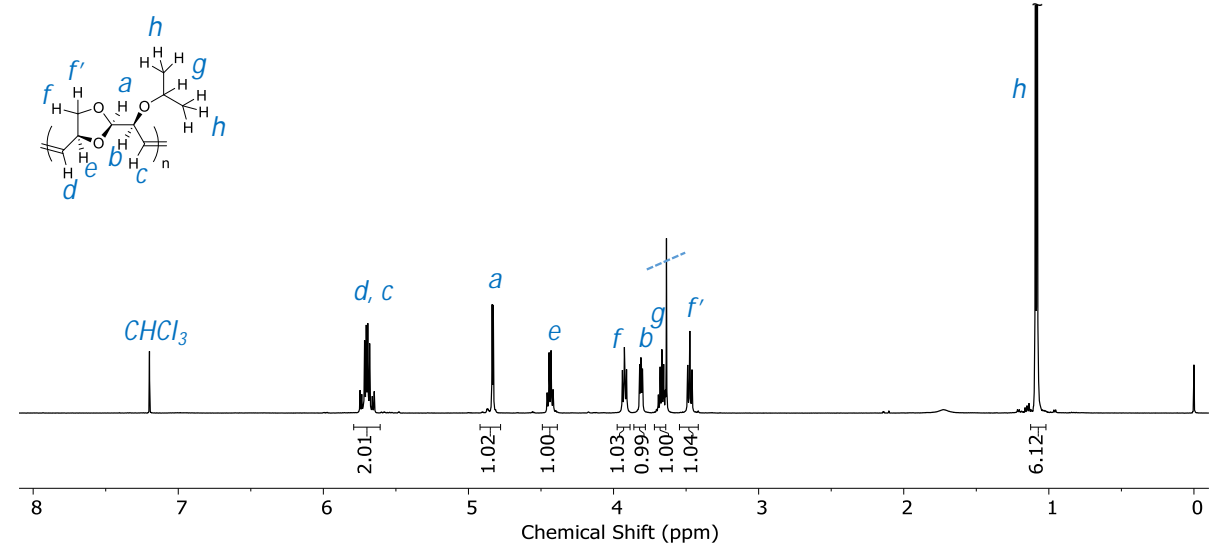

Figure S37. ${ }^{1} \mathrm{H}$ NM R (500 M Hz) spectrum of poly(levoglucosenyl isopropyl ether) $3 e$ in $\mathrm{CDCl}_{3}$.

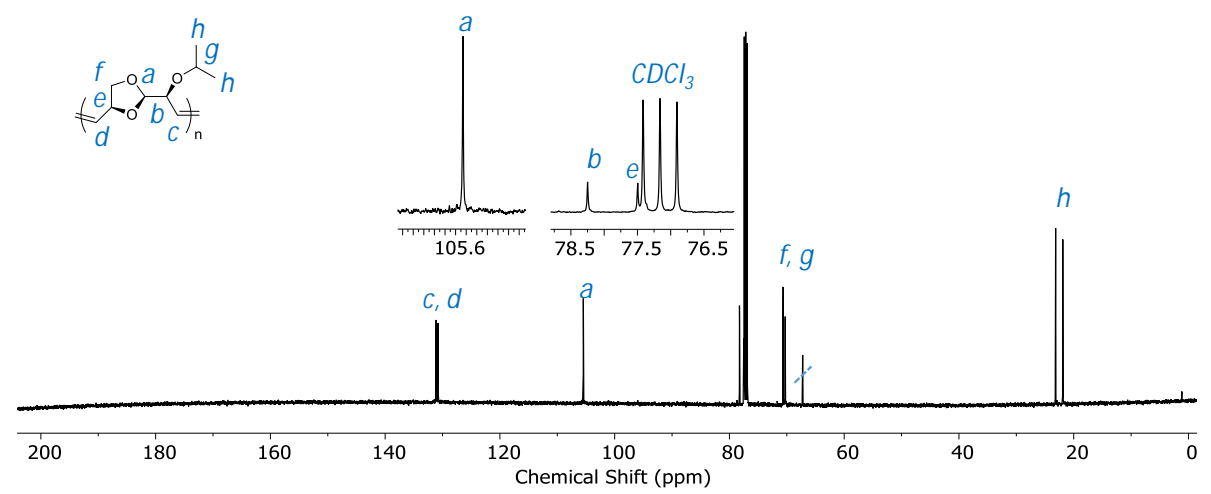

Figure S38. ${ }^{13} \mathrm{C}$ NM R (126 M Hz) spectrum of poly(levoglucosenyl isopropyl ether) $3 e$ in $\mathrm{CDCl}_{3}$.

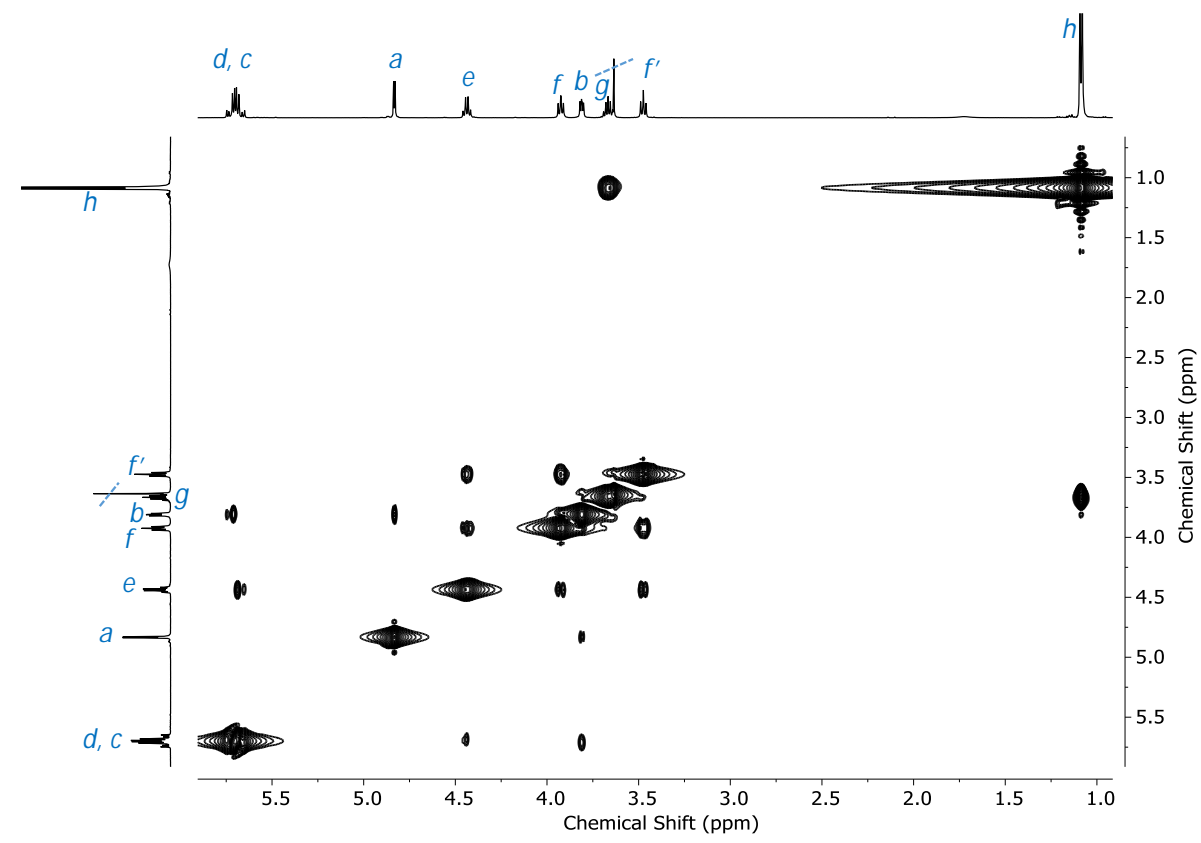

Figure S39. ${ }^{1} \mathrm{H}-{ }^{1} \mathrm{H}$ COSY NM R (500M Hz) spectrum of poly(levoglucosenyl isopropyl ether) $3 e$ in DM SO-d6. 


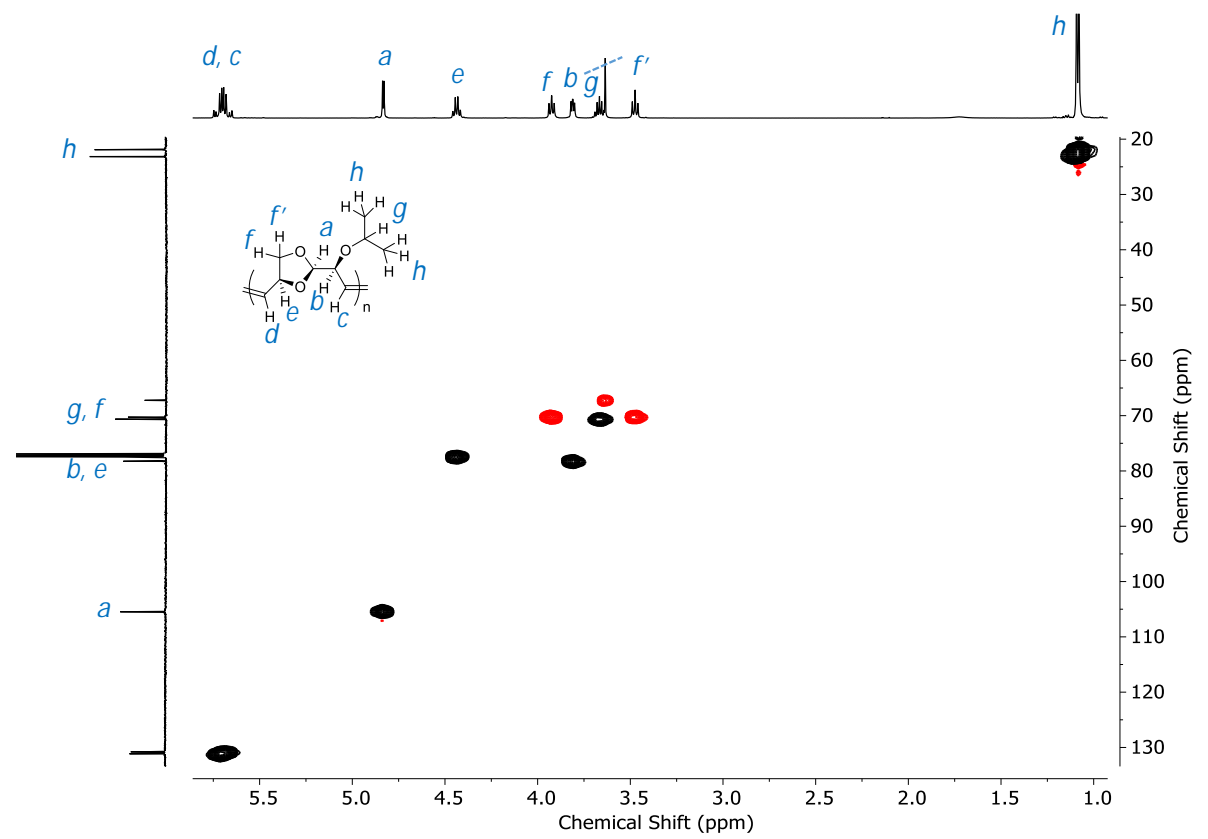

Figure $\mathrm{S} 40 .{ }^{1} \mathrm{H}-{ }^{13} \mathrm{C} \mathrm{HSQC} \mathrm{NM} \mathrm{R}(500 \mathrm{M} \mathrm{Hz})$ spectrum of poly(levoglucosenyl isopropyl ether) $3 e$ in DM SO- $\mathrm{d}_{6}$.
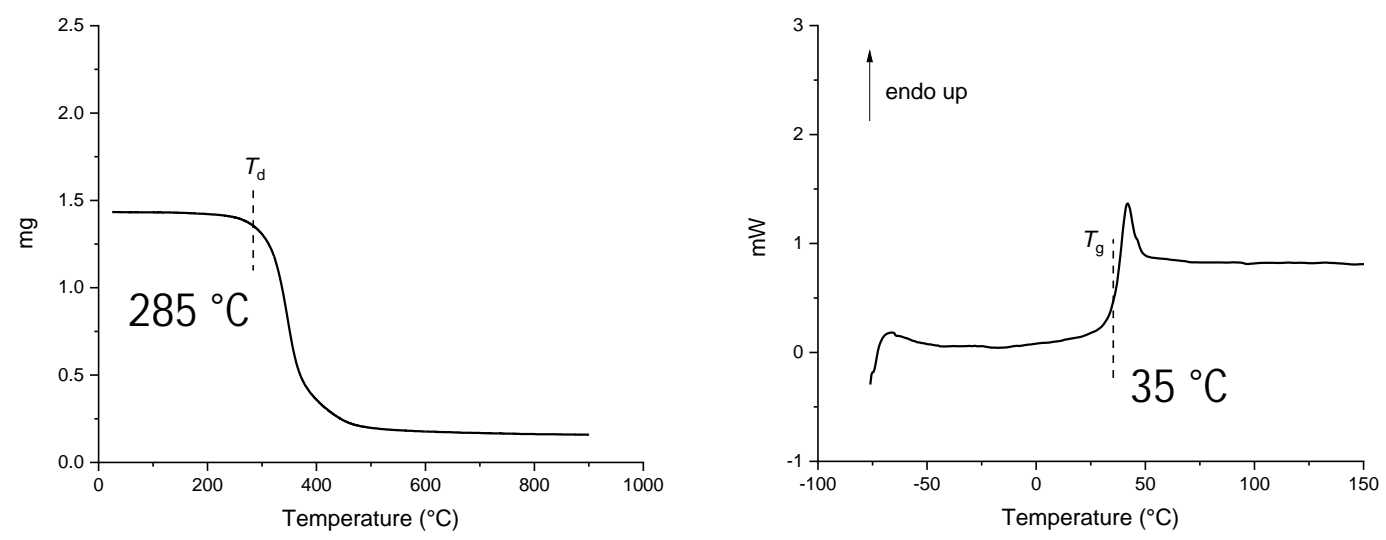

Figure S41. TGA curve (left) and DSC third heating curve (right) of poly(levoglucosenyl isopropyl ether) $3 e$. 
Polymerization of levoglucosenyl n-butyl ether $\mathbf{2 f}$ in 1,4-dioxane
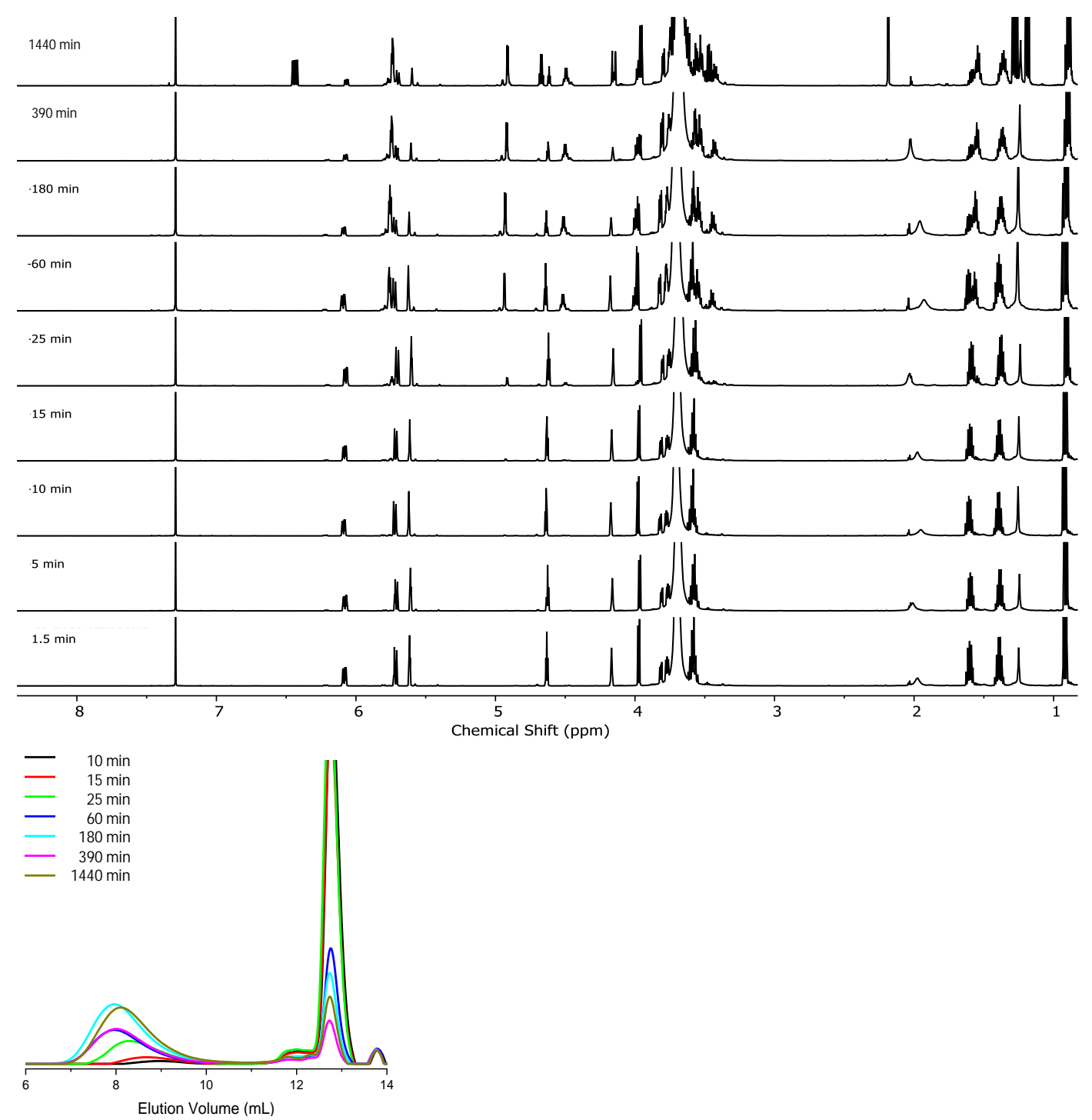

Figure S42. ${ }^{1} \mathrm{H}$ NMR (600 M Hz) spectra (top) and SEC-RI traces (bottom) of reaction mixtures taken during the polymerization of levoglucosenyl n-butyl ether $\mathbf{2 f}$ (4 mmol) with catalyst C793 (0.04 mmol) in 1,4-dioxane (1 $\mathrm{mL})$ solution at room temperature. Samples were quenched with ethyl vinyl ether and diluted with $\mathrm{CDCl}_{3}$ (NM R) or THF (SEC).
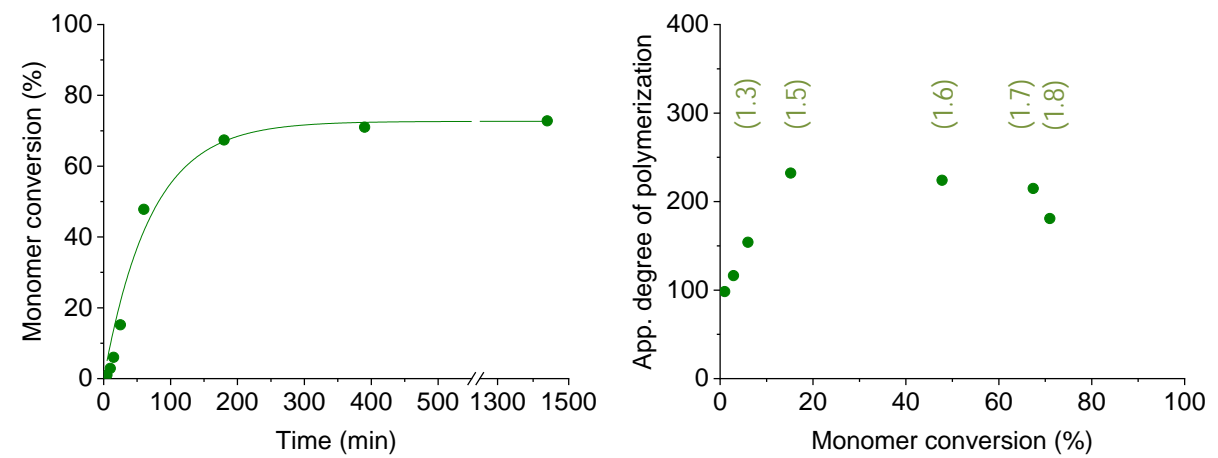

Figure S43. Polymerization of levoglucosenyl n-butyl ether $\mathbf{2 f}$ ( $4 \mathrm{mmol}$ ) with catalyst C793 (0.04 mmol) in 1,4-dioxane at room temperature: time-conversion plot (monomer conversions were determined by ${ }^{1} \mathrm{H}$ NMR analysis) (left) and evolution of the apparent number-average degree of polymerization and dispersity (as determined by SEC) as function of monomer conversion (right). 
Poly(levoglucosenyl n-butyl ether) $\mathbf{3 f}$ (purified sample produced at $1440 \mathrm{~min}$ )

${ }^{1} \mathrm{H} \mathrm{NM} \mathrm{R}\left(500 \mathrm{M} \mathrm{Hz}, \mathrm{CDCl}_{3}\right) \delta 5.81-5.46(\mathrm{~m}, 2 \mathrm{H}), 4.94-4.82(\mathrm{~m}, 1 \mathrm{H}), 4.53-4.34(\mathrm{~m}, 1 \mathrm{H}), 3.96-3.89(\mathrm{~m}, 1 \mathrm{H})$, 3.77-3.67 (m, 1H), 3.57-3.44 (m, 2H), 3.44-3.30 (m, 1H), 1.54-1.44 (m, 1H), 1.34-1.24 (m, 2H), 0.87-0.79 (m, 3H). ${ }^{13} \mathrm{C} \mathrm{NMR}\left(126 \mathrm{M} \mathrm{Hz}, \mathrm{CDCl}_{3}\right) \delta 131.41,130.61,105.27,80.89,77.52,70.20,69.80,67.23,32.01$, $19.43,14.05,19.23$.

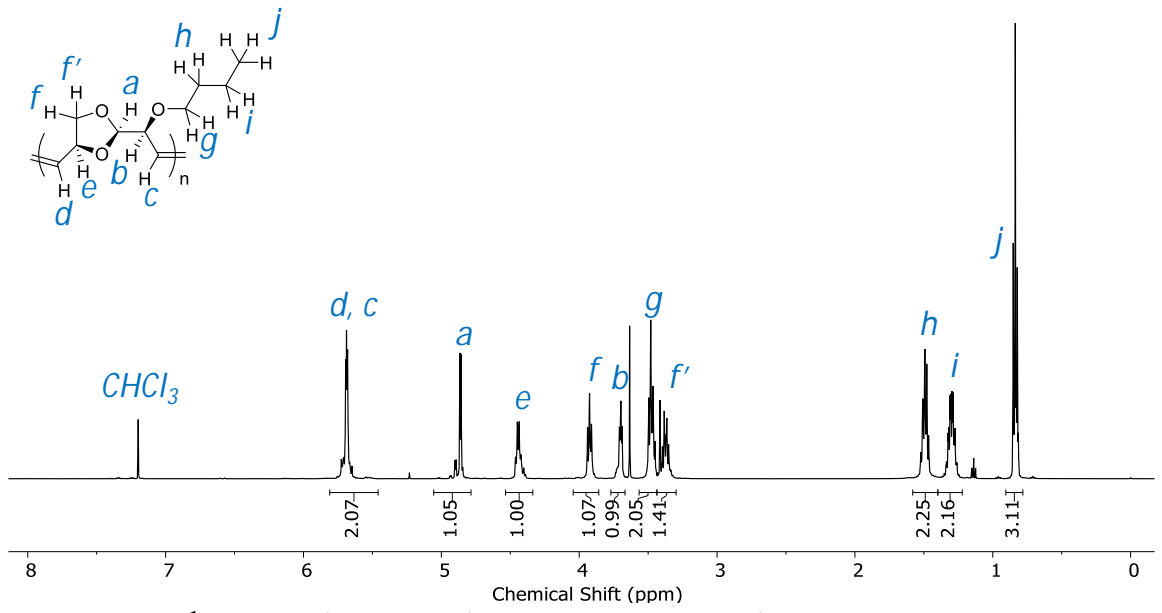

Figure S44. ${ }^{1} \mathrm{H}$ NMR (500 M Hz) spectrum of poly(levoglucosenyl n-butyl ether) $\mathbf{3 f}$ in $\mathrm{CDCl}_{3}$.

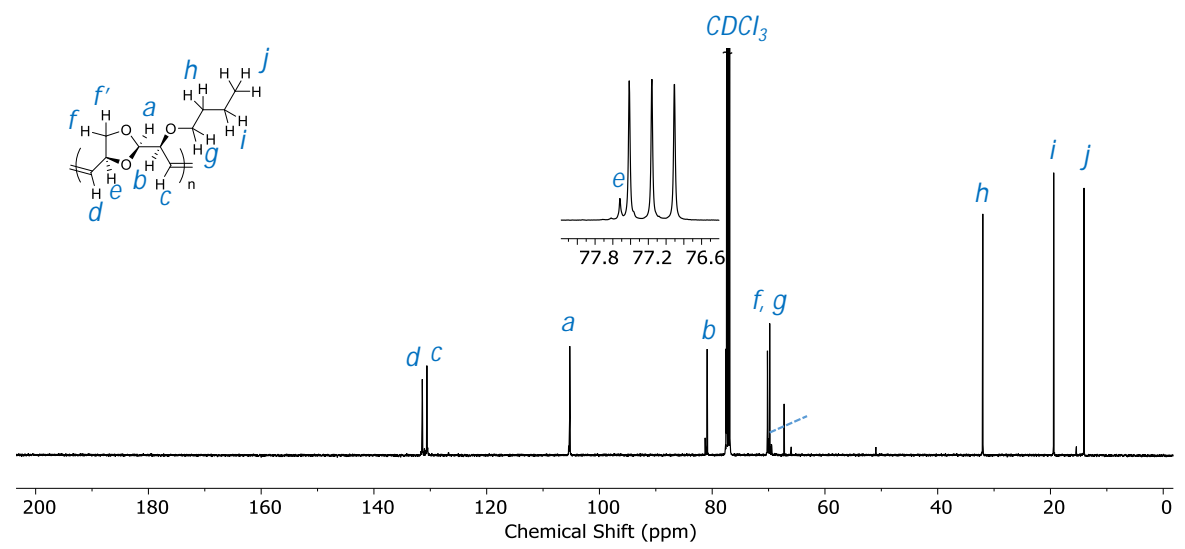

Figure S45. ${ }^{13} \mathrm{C}$ NM R (126 M Hz) spectrum of poly(levoglucosenyl n-butyl ether) $\mathbf{3 f}$ in $\mathrm{CDCl}_{3}$.

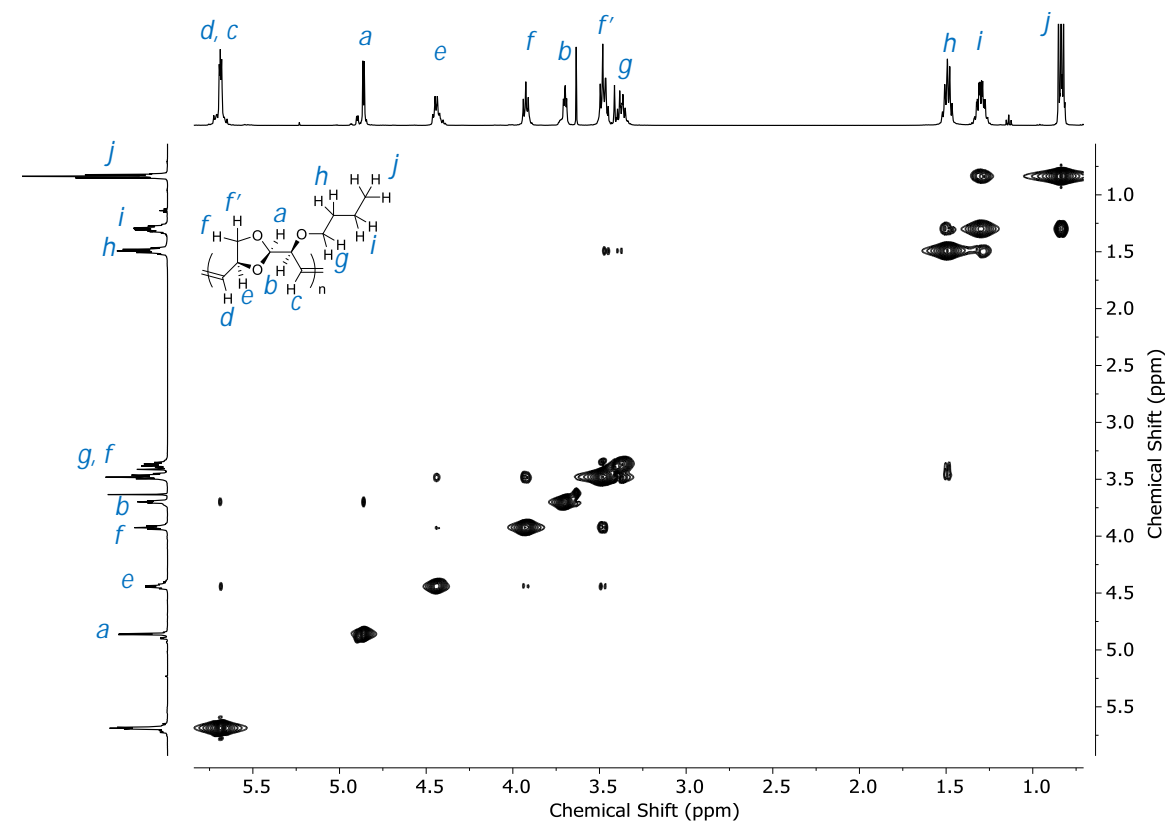

Figure $\mathrm{S}_{6}{ }^{1} \mathrm{H}^{-1} \mathrm{H}$ COSY NM R $(500 \mathrm{M} \mathrm{Hz})$ spectrum of poly(levoglucosenyl $n$-butyl ether) $3 \mathbf{f}$ in DM SO-d . 


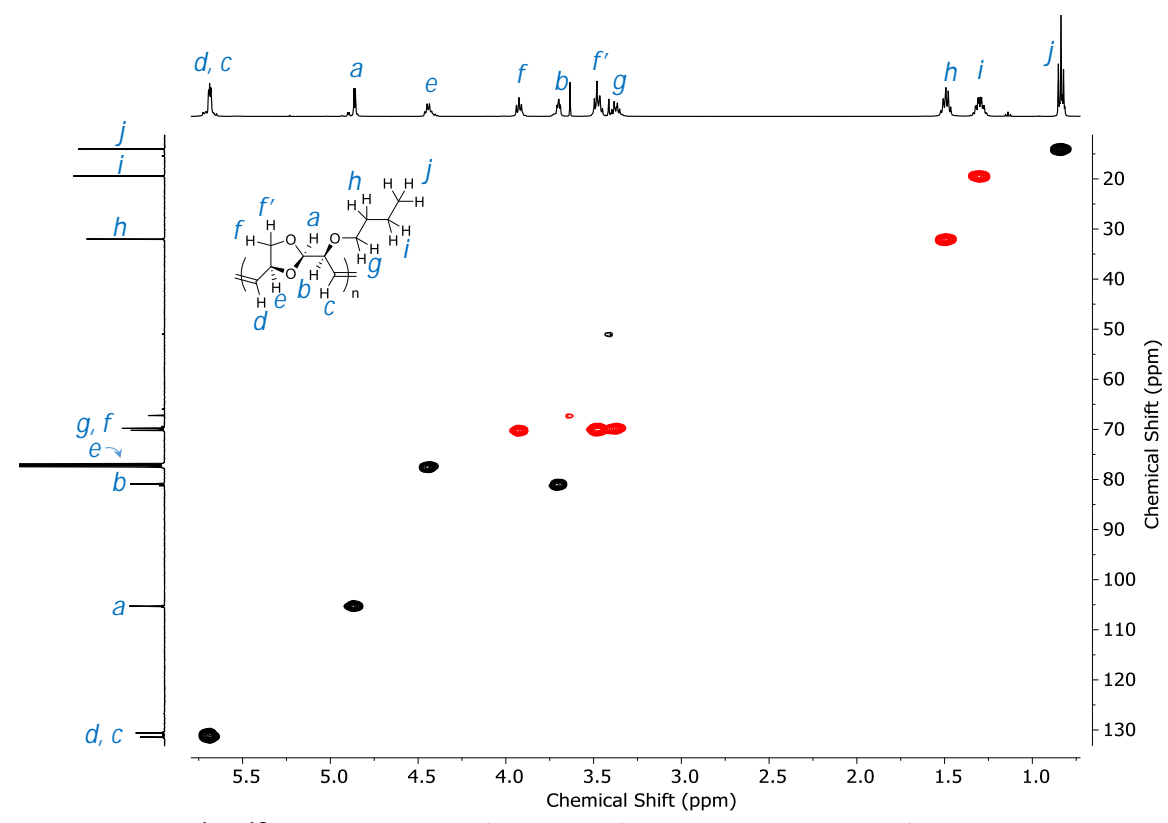

Figure S47. ${ }^{1} \mathrm{H}-{ }^{13} \mathrm{C}$ HSQC NM R (500M Hz) spectrum of poly(levoglucosenyl $n$-butyl ether) $3 \mathbf{f}$ in DM SO-d6.
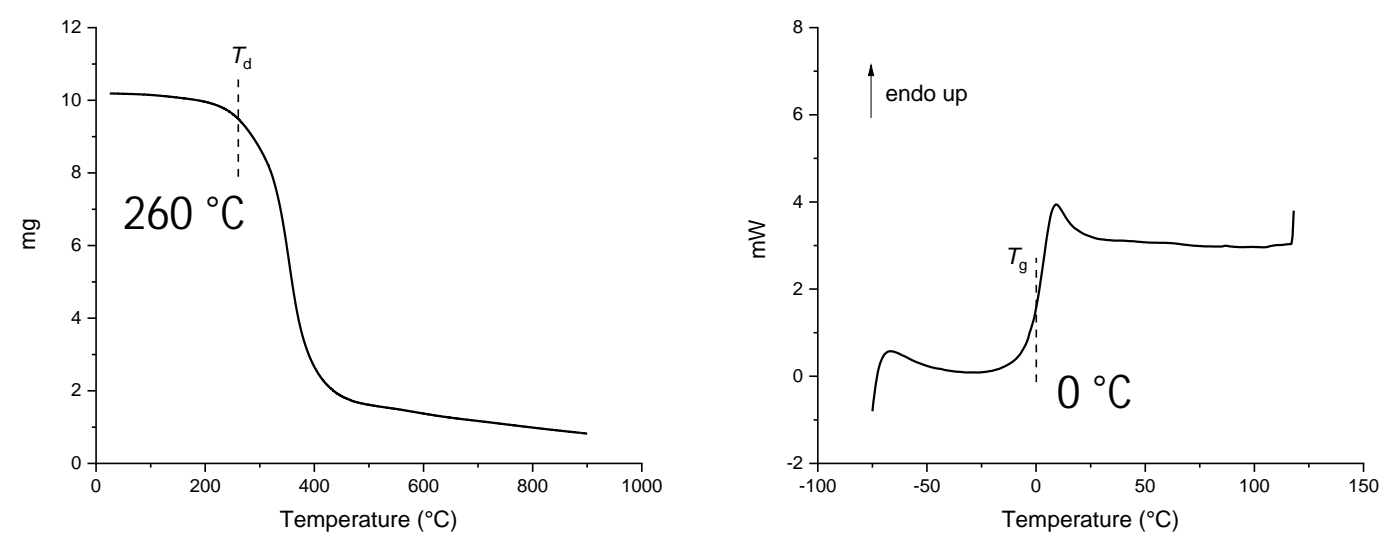

Figure S48. TGA (left) and DSC third heating curve (right) of poly(levoglucosenyl n-butyl ether) $\mathbf{3 f}$. 
Polymerization of levoglucosenyl methyl ether $\mathbf{2} \mathbf{b}$ in DCM.

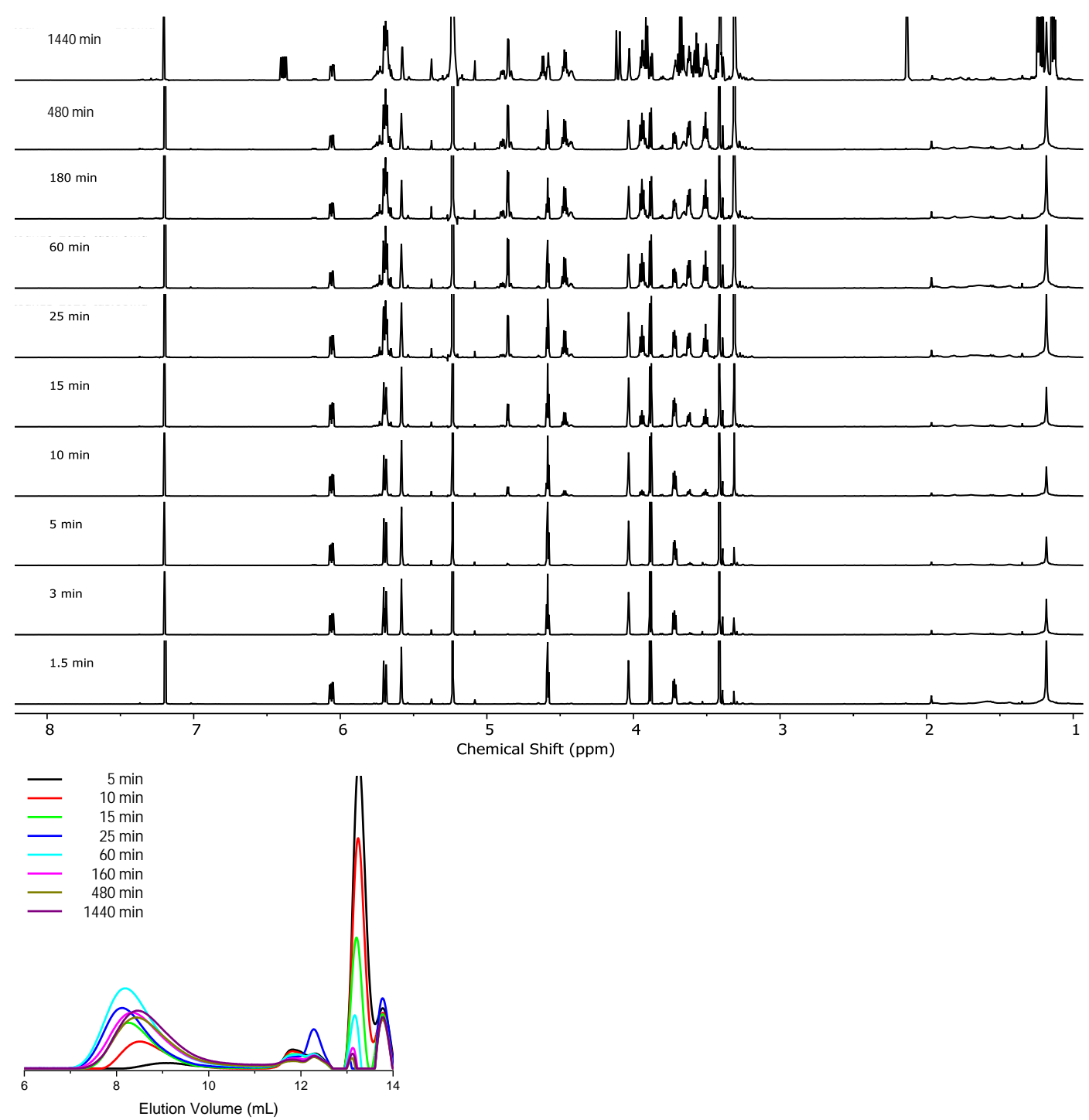

Figure S49. ${ }^{1} \mathrm{H}$ NMR (600 M Hz) spectra (top) and SEC-RI traces (bottom) of reaction mixtures taken during the polymerization of levoglucosenyl methyl ether $\mathbf{2 b}(5 \mathrm{mmol})$ with catalyst C793 $(0.05 \mathrm{mmol})$ in DCM $(1.25 \mathrm{~mL})$ solution at room temperature. Samples were quenched with ethyl vinyl ether and diluted with $\mathrm{CDCl}_{3}$ (NM R) or THF (SEC).
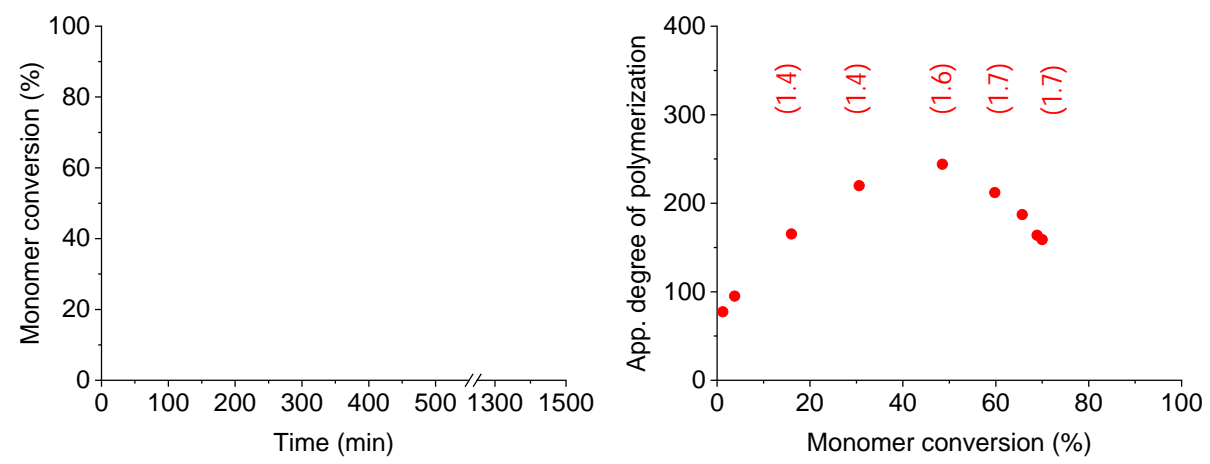

Figure S50. Polymerization of levoglucosenyl methyl ether $\mathbf{2 b}$ ( 5 mmol) with catalyst C793 ( $0.05 \mathrm{mmol}$ ) in DCM at room temperature: time-conversion plot (monomer conversions were determined by ${ }^{1} \mathrm{H}$ NMR analysis) (left) and evolution of the apparent number-average degree of polymerization and dispersity (as determined by SEC) as function of monomer conversion (right). 
Polymerization of levoglucosenyl methyl ether $\mathbf{2 b}$ in 2-M eTHF.

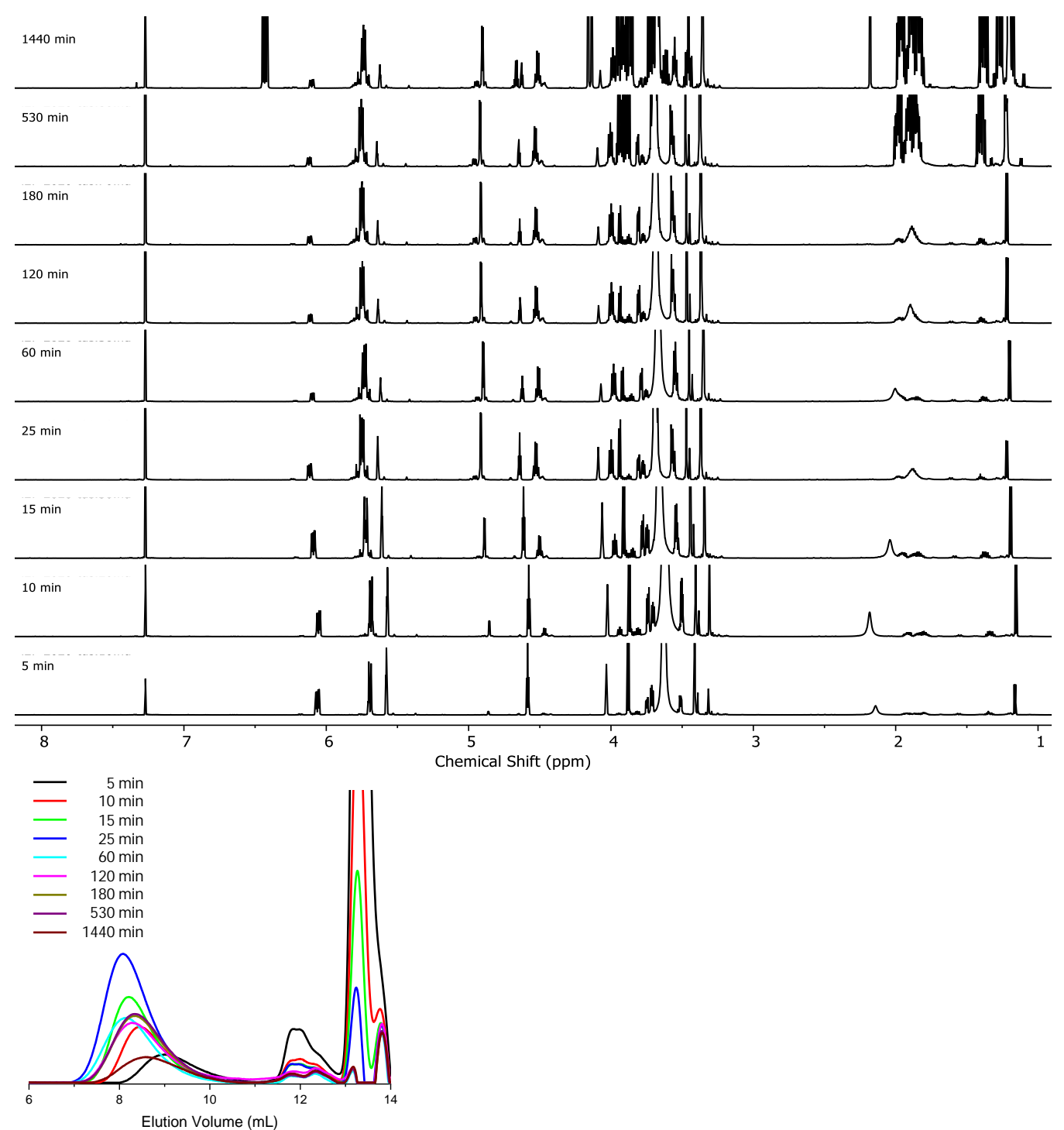

Figure S51. ${ }^{1} \mathrm{H}$ NM R (600 M Hz) spectra (top) and SEC-RI traces (bottom) of reaction mixtures taken during the polymerization of levoglucosenyl methyl ether $\mathbf{2} \mathbf{b}$ ( $5 \mathrm{mmol}$ ) with catalyst C793 ( $0.05 \mathrm{mmol})$ in 2-M eTHF (1.25 mL) solution at room temperature. Samples were quenched with ethyl vinyl ether and diluted with $\mathrm{CDCl}_{3}$ (NM R) or THF (SEC).
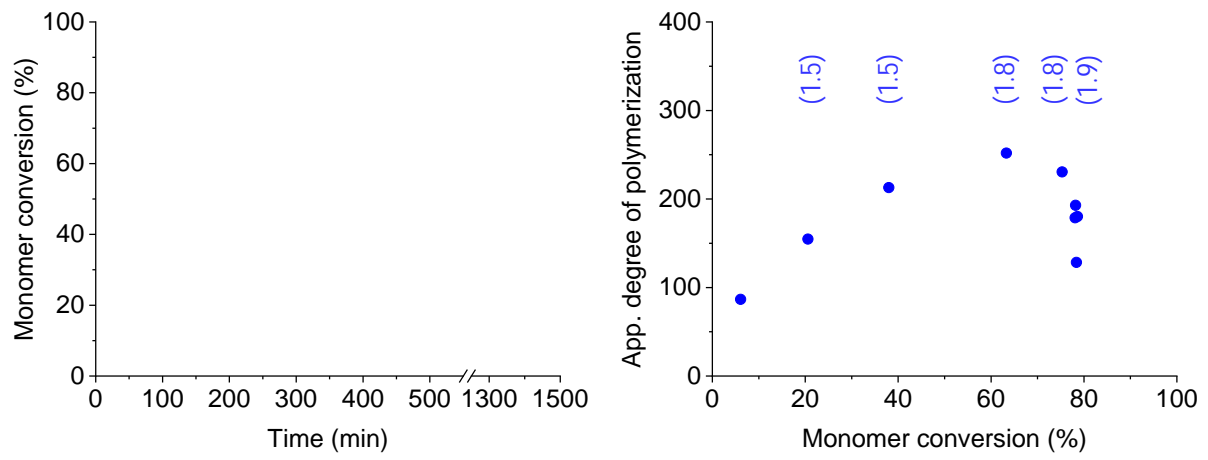

Figure S52. Polymerization of levoglucosenyl methyl ether $\mathbf{2 b}$ ( $5 \mathrm{mmol}$ ) with catalyst C793 (0.05 mmol) in 2-M eTHF at room temperature: time-conversion plot (monomer conversions were determined by ${ }^{1} \mathrm{H}$ NM R analysis) (left) and evolution of the apparent number-average degree of polymerization and dispersity (as determined by SEC) as function of monomer conversion (right). 
Polymerization of levoglucosenyl methyl ether $\mathbf{2} \mathbf{b}$ in Cyrene.

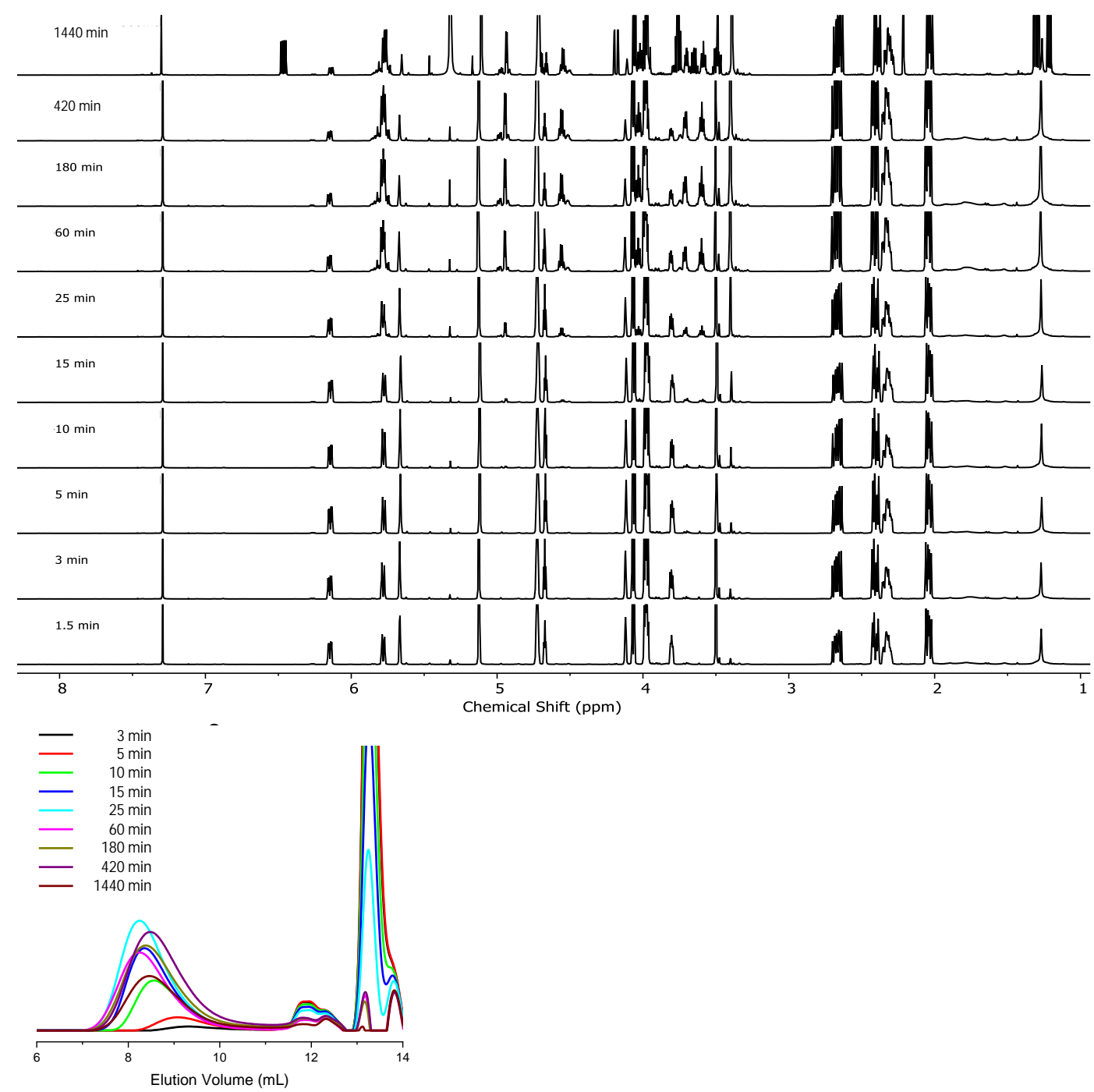

Figure S53. ${ }^{1} \mathrm{H}$ NMR (600 M Hz) spectra (top) and SEC-RI traces (bottom) of reaction mixtures taken during the polymerization of levoglucosenyl methyl ether $\mathbf{2} \mathbf{b}$ ( $5 \mathrm{mmol}$ ) with catalyst C793 (0.05 mmol) in Cyrene $(1.25 \mathrm{~mL})$ solution at room temperature. Samples were quenched with ethyl vinyl ether and diluted with $\mathrm{CDCl}_{3}$ (NM R) or THF (SEC).
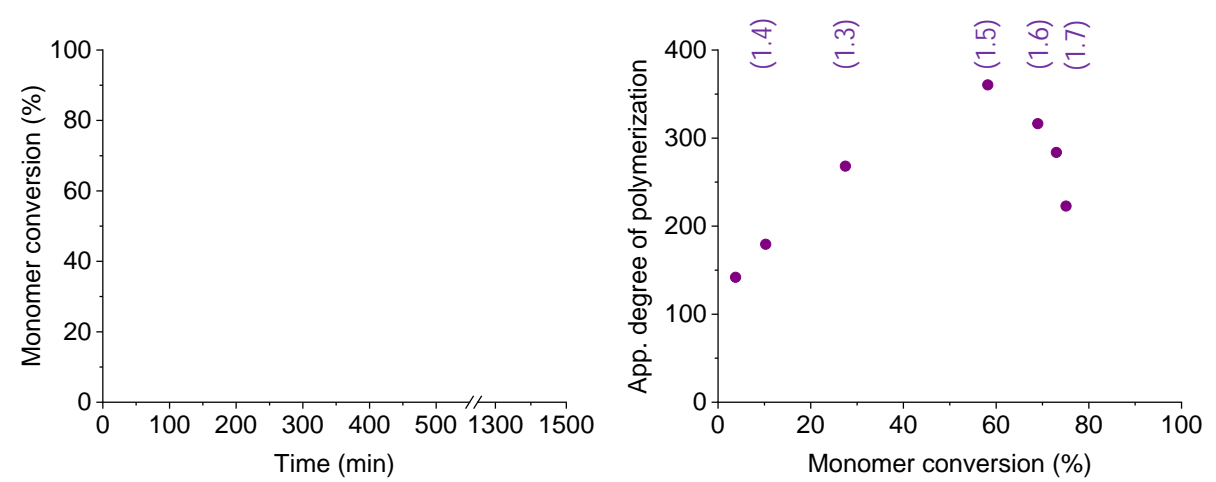

Figure S54. Polymerization of levoglucosenyl methyl ether $\mathbf{2} \mathbf{b}$ ( $5 \mathrm{mmol}$ ) with catalyst C793 (0.05 mmol) in Cyrene at room temperature: time-conversion plot (monomer conversions were determined by ${ }^{1} \mathrm{H}$ NMR analysis) (left) and evolution of the apparent number-average degree of polymerization and dispersity (as determined by SEC) as function of monomer conversion (right). 
$\underline{\text { Polymerization of levoglucosenyl methyl ether } \mathbf{2} \mathbf{b} \text { in ethyl acetate. }}$

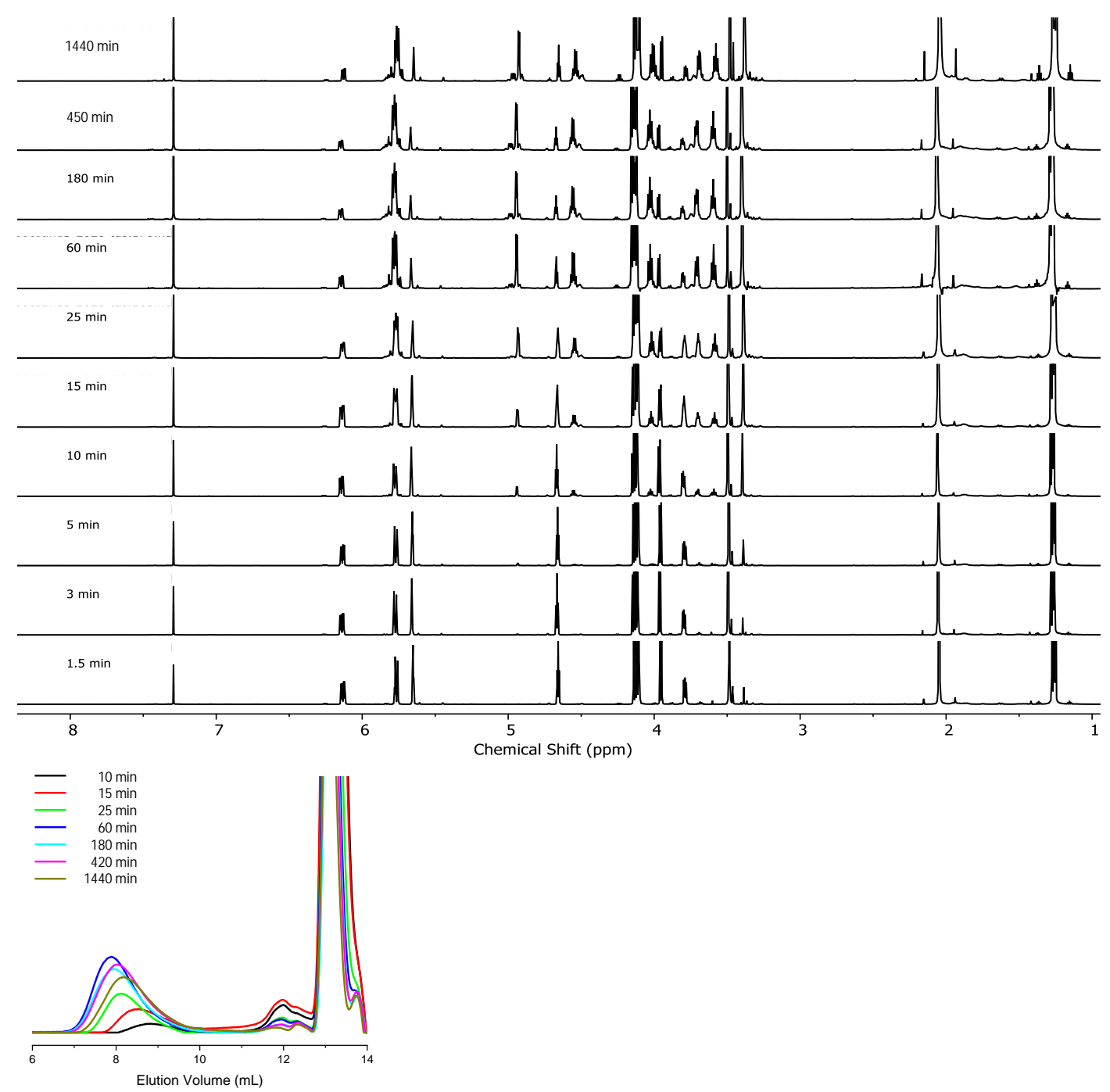

Figure S55. ${ }^{1} \mathrm{H}$ NM R (600 M Hz) spectra (top) and SEC-RI traces (bottom) of reaction mixtures taken during the polymerization of levoglucosenyl methyl ether $\mathbf{2} \mathbf{b}$ ( $5 \mathrm{mmol}$ ) with catalyst C793 $(0.05 \mathrm{mmol})$ in ethyl acetate $(1.25 \mathrm{~mL})$ solution at room temperature. Samples were quenched with ethyl vinyl ether and diluted with $\mathrm{CDCl}_{3}$ (NM R) or THF (SEC).
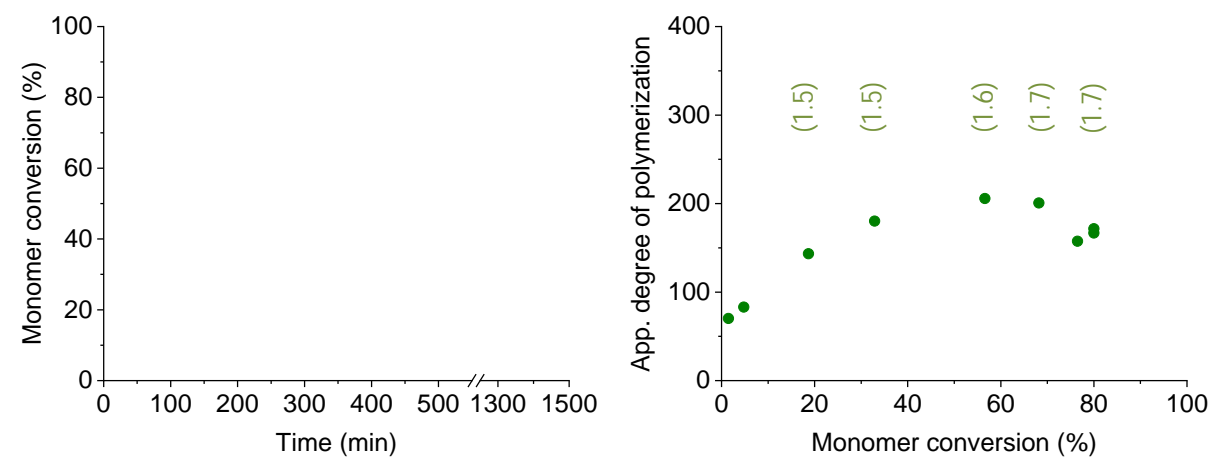

Figure S56. Polymerization of levoglucosenyl methyl ether $\mathbf{2 b}$ ( $5 \mathrm{mmol}$ ) with catalyst C793 ( $0.05 \mathrm{mmol}$ ) in ethyl acetate at room temperature: time-conversion plot (monomer conversions were determined by ${ }^{1} \mathrm{H}$ NMR analysis) (left) and evolution of the apparent number-average degree of polymerization and dispersity (as determined by SEC) as function of monomer conversion (right). 
Polymerization of levoglucosenyl methyl ether $\mathbf{2 b}(2 \mathrm{mmol})$ with $\mathrm{C793}(0.02 \mathrm{mmol})$ in 1,4-dioxane- $\mathrm{d}_{8}$

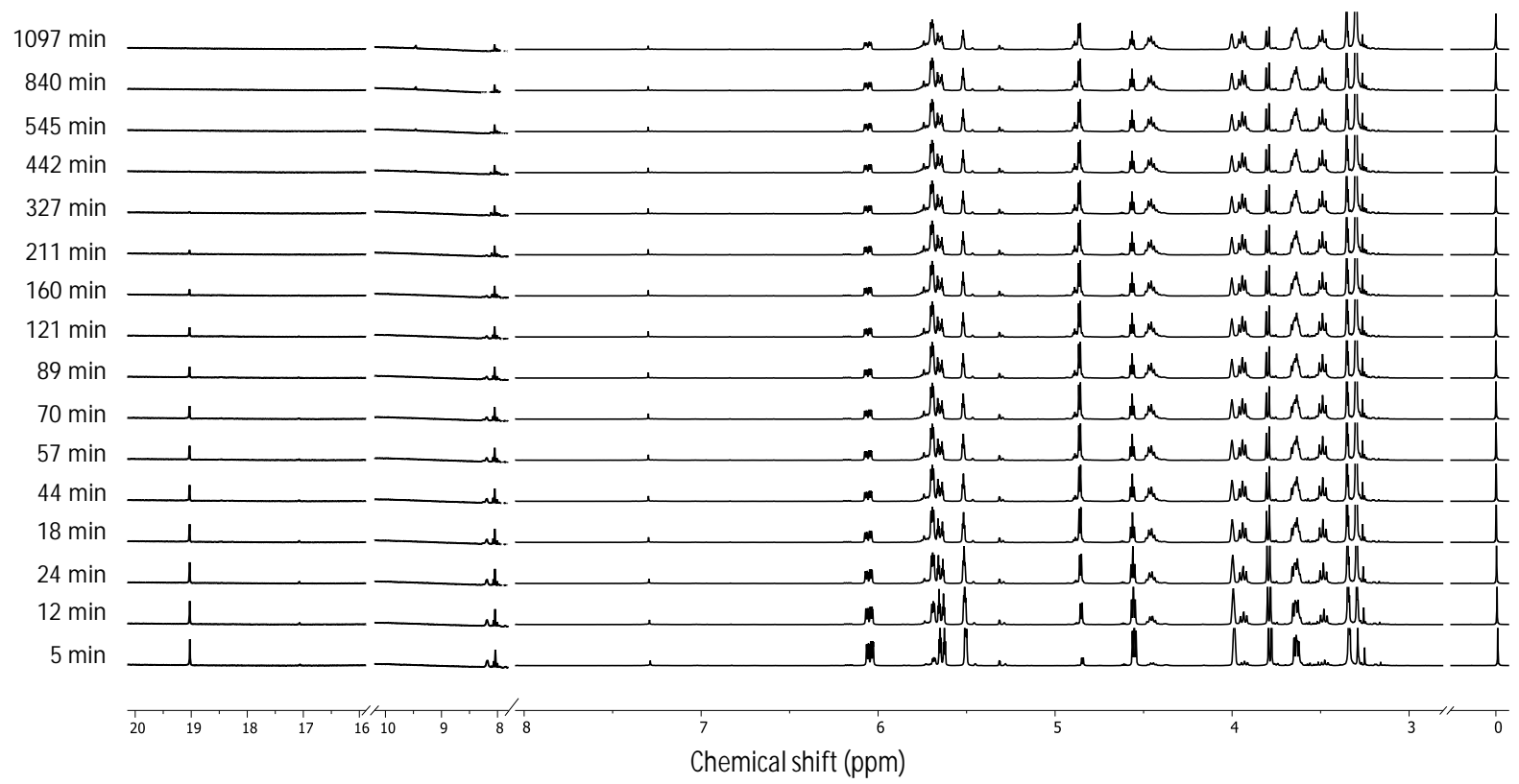

Figure S57. In situ kinetic experiment: ${ }^{1} \mathrm{H}$ NMR $(400 \mathrm{MHz})$ spectra of the polymerization of levoglucosenyl methyl ether $\mathbf{2 b}(2 \mathrm{mmol})$ with catalyst $\mathrm{C} 793(0.02 \mathrm{mmol})$ in 1,4-dioxane- $\mathrm{d}_{8}(0.5 \mathrm{~mL}$, containing HM D as internal standard) solution at room temperature.

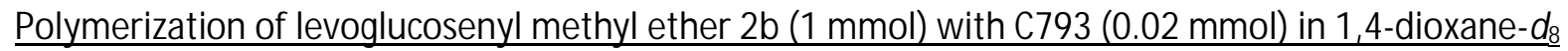

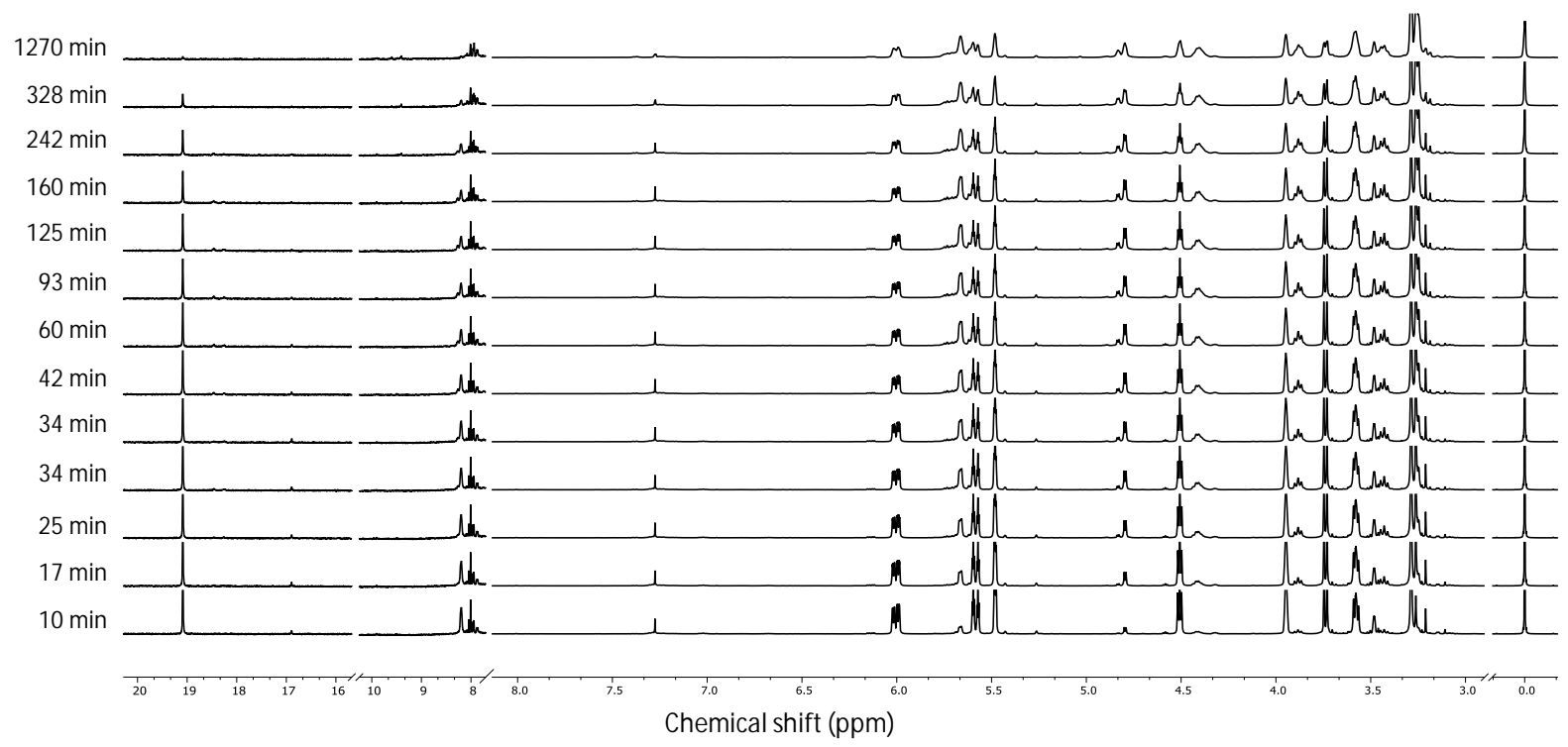

Figure S58. In situ kinetic experiment: ${ }^{1} \mathrm{H}$ NMR $(400 \mathrm{MHz})$ spectra of the polymerization of levoglucosenyl methyl ether $\mathbf{2 b}(1 \mathrm{mmol})$ with catalyst $\mathrm{C} 793(0.02 \mathrm{mmol})$ in 1,4-dioxane- $\mathrm{d}_{8}(0.5 \mathrm{~mL}$, containing HM D as internal standard) solution at room temperature. 
Polymerization of levoglucosenyl methyl ether $\mathbf{2 b}(0.5 \mathrm{mmol})$ with $\mathrm{C} 793(0.02 \mathrm{mmol})$ in 1,4-dioxane- $\mathrm{d}_{8}$

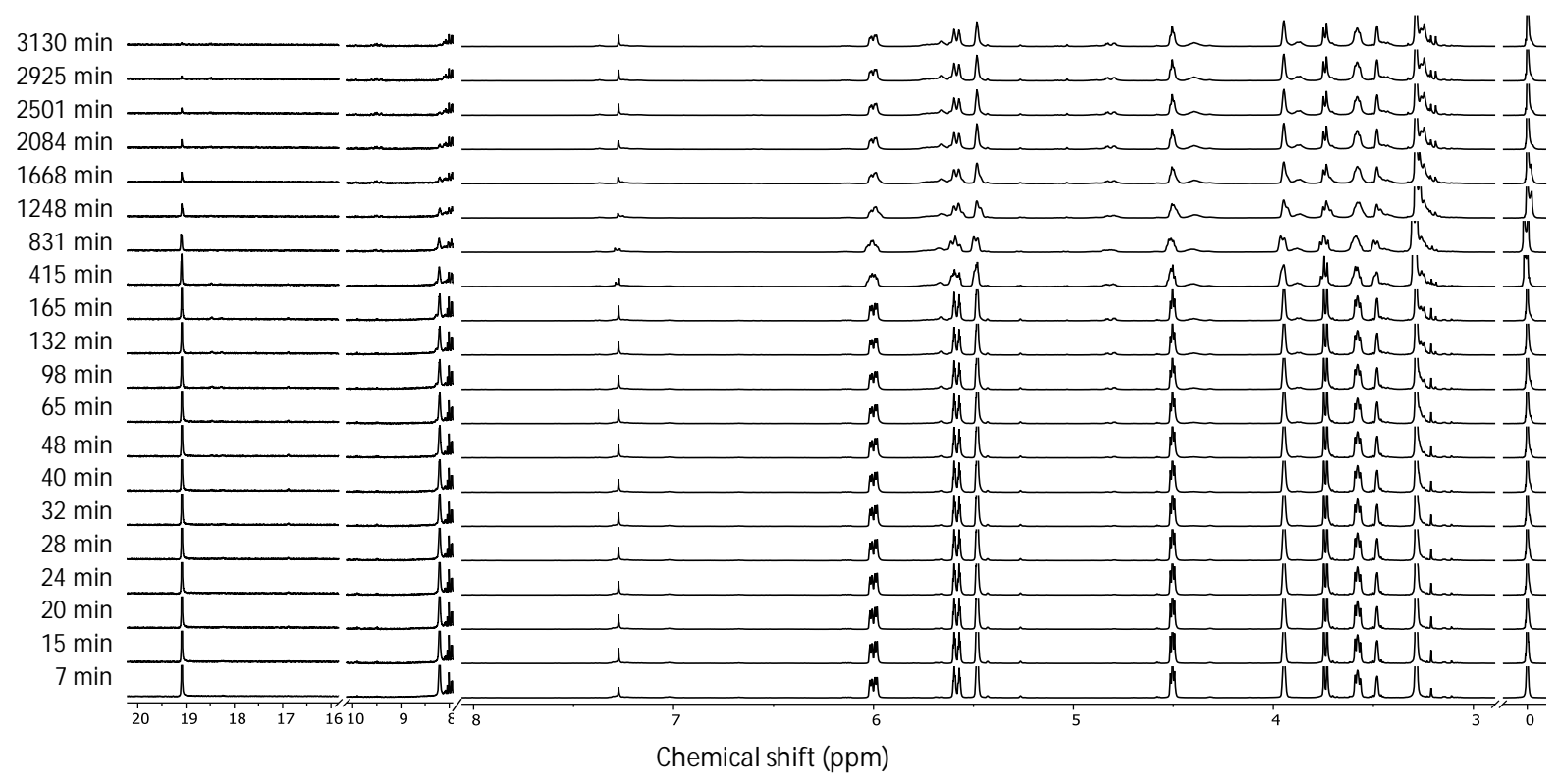

Figure S59. In situ kinetic experiment: ${ }^{1} \mathrm{H}$ NMR $(400 \mathrm{MHz})$ spectra of the polymerization of levoglucosenyl methyl ether $\mathbf{2 b}(0.5 \mathrm{mmol})$ with catalyst $\mathrm{C} 793(0.02 \mathrm{mmol})$ in 1,4-dioxane- $\mathrm{d}_{8}(0.5 \mathrm{~mL}$, containing HM D as internal standard) solution at room temperature.

Polymerization of levoglucosenyl methyl ether $\mathbf{2 b}$ (1 mmol) with $\mathrm{C793}(0.04 \mathrm{mmol})$ in 1,4-dioxane- $\mathrm{d}_{8}$

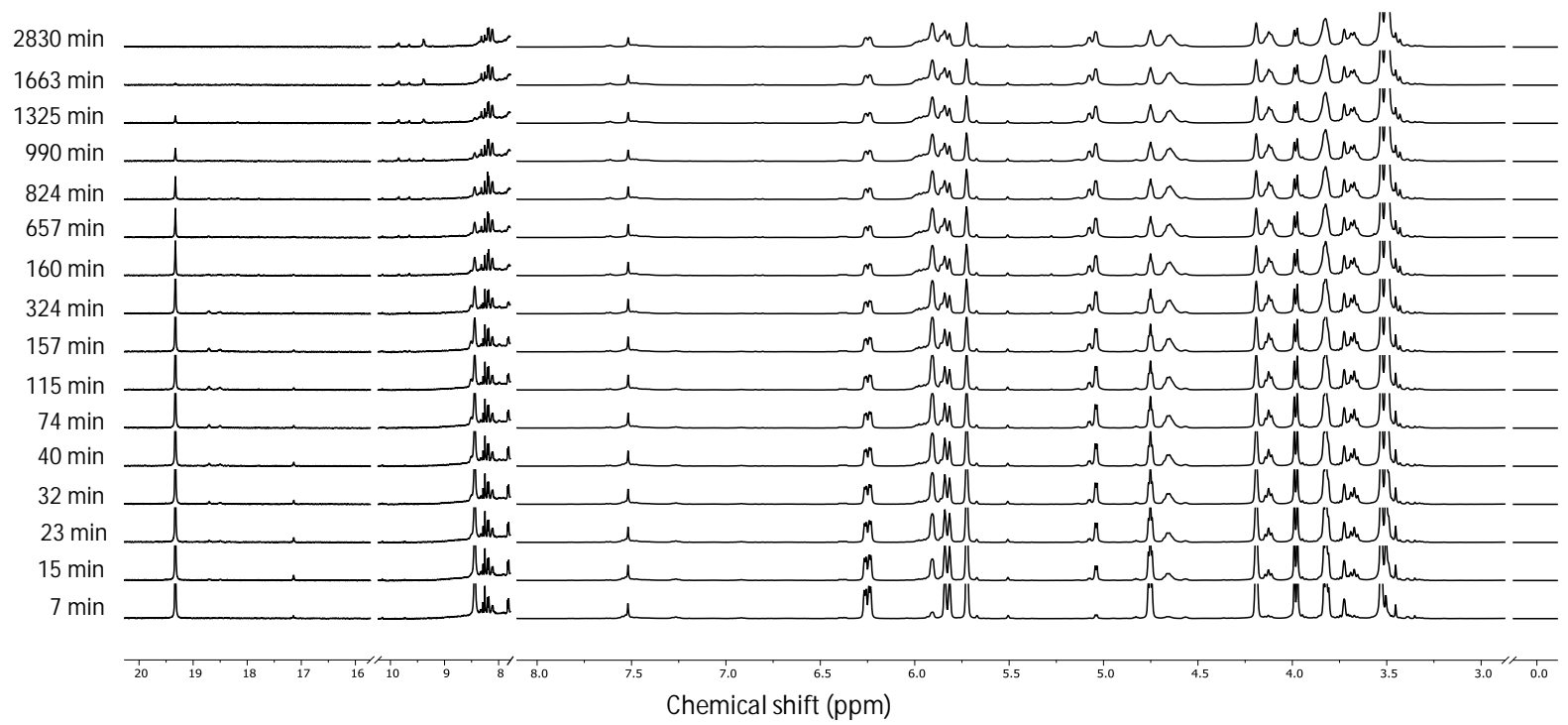

Figure S60. In situ kinetic experiment: ${ }^{1} \mathrm{H}$ NMR $(400 \mathrm{MHz})$ spectra of the polymerization of levoglucosenyl methyl ether $\mathbf{2 b}(1 \mathrm{mmol})$ with catalyst $\mathrm{C} 793(0.04 \mathrm{mmol})$ in 1,4-dioxane- $\mathbf{d}_{8}(0.5 \mathrm{~mL}$, containing no HMD, internal standard: solvent peak at $\delta 3.53 \mathrm{ppm}$ ) solution at room temperature. (See also Figure 6.) 
Polymerization of levoglucosenyl methyl ether $\mathbf{2 b}(1 \mathrm{mmol})$ with C793 $(0.01 \mathrm{mmol})$ in 1,4-dioxane-d

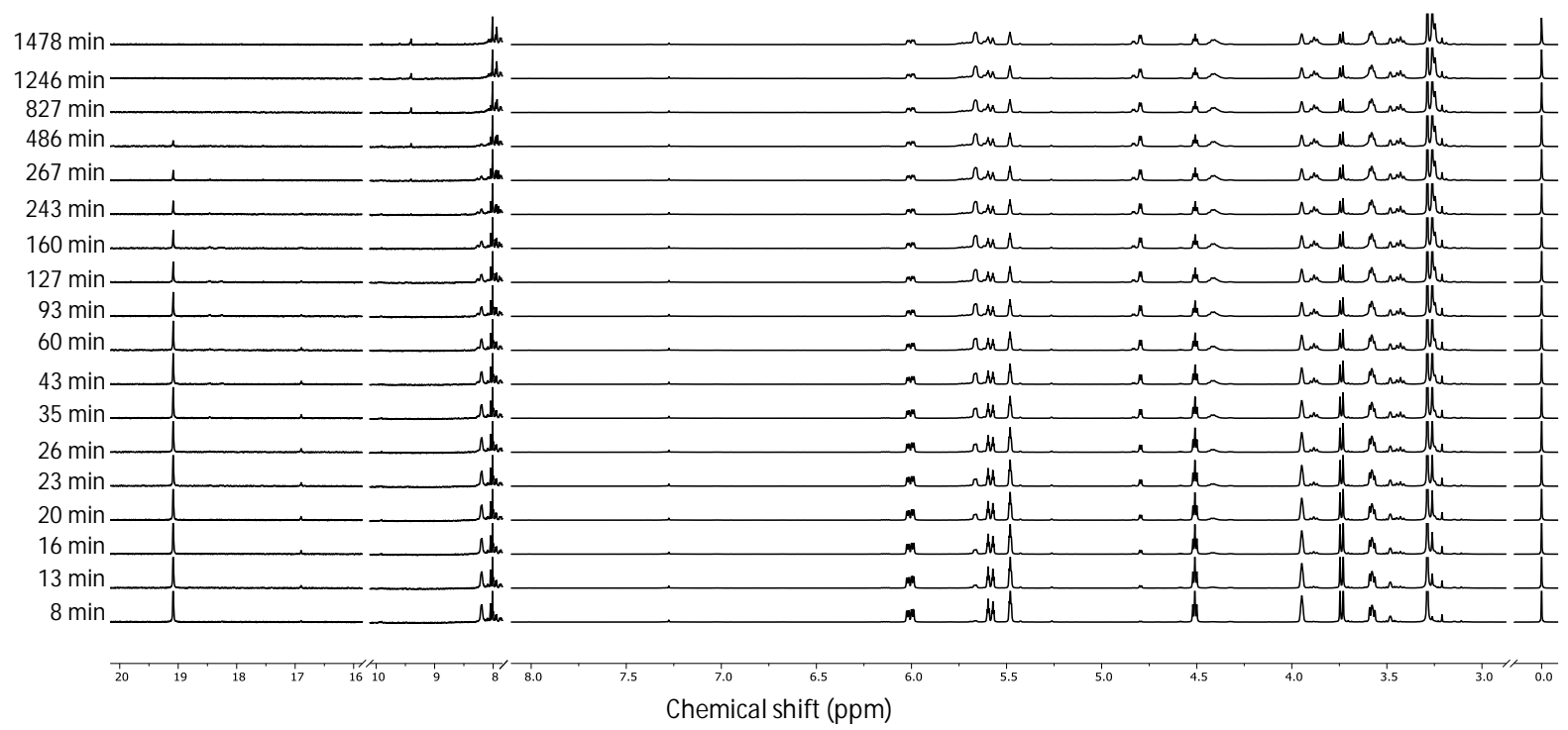

Figure S61. In situ kinetic experiment: ${ }^{1} \mathrm{H}$ NMR (400 MHz) spectra of the polymerization of levoglucosenyl methyl ether $\mathbf{2 b}(1 \mathrm{mmol})$ with catalyst $\mathrm{C} 793(0.01 \mathrm{mmol})$ in 1,4-dioxane- $\mathrm{d}_{8}(0.5 \mathrm{~mL}$, containing HMD as internal standard) solution at room temperature. 


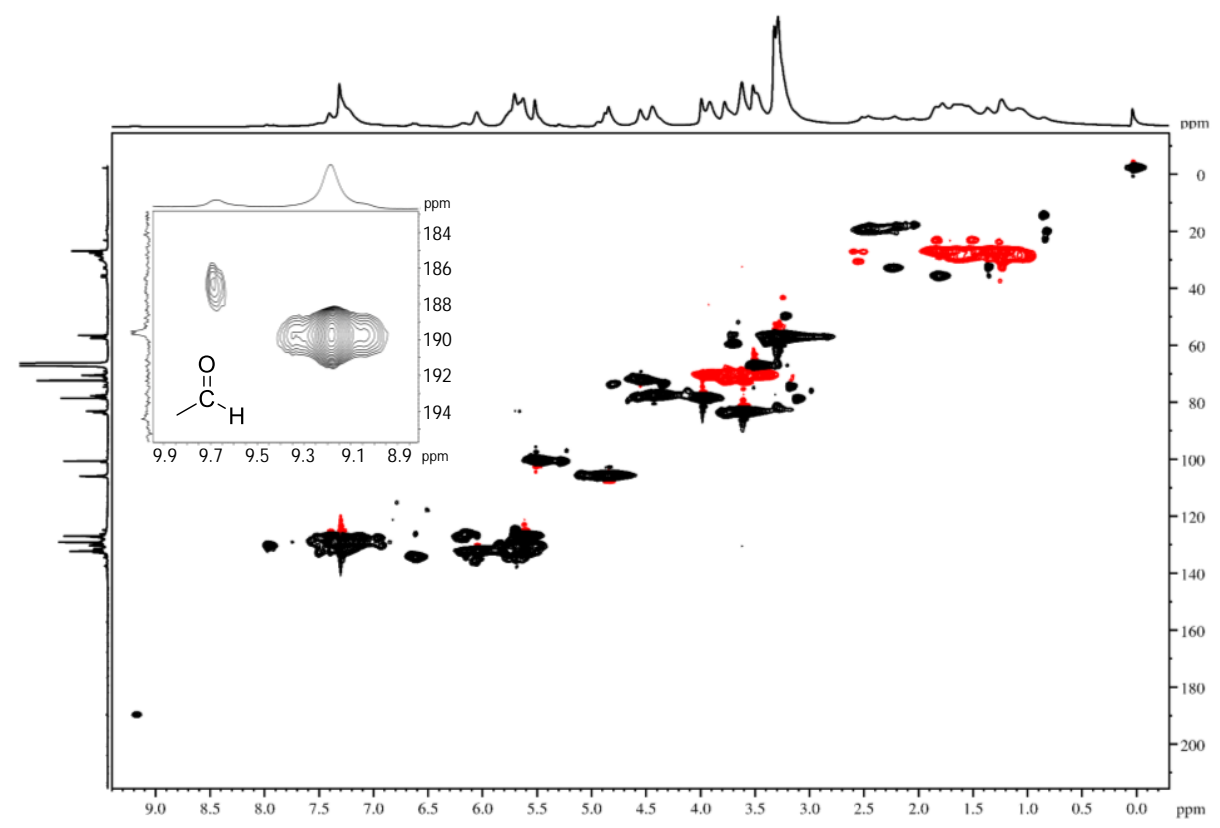

Figure S62. ${ }^{1 \mathrm{H}-}{ }^{13} \mathrm{C}$ HSQC NMR $(600 \mathrm{MHz})$ spectrum of the crude reaction mixture containing levoglucosenyl methyl ether $\mathbf{2 b}(1 \mathrm{mmol})$, catalyst $\mathrm{C} 793(0.2 \mathrm{mmol})$ in 1,4-dioxane- $\mathrm{d}_{8}(0.5 \mathrm{~mL})$ at room temperature.

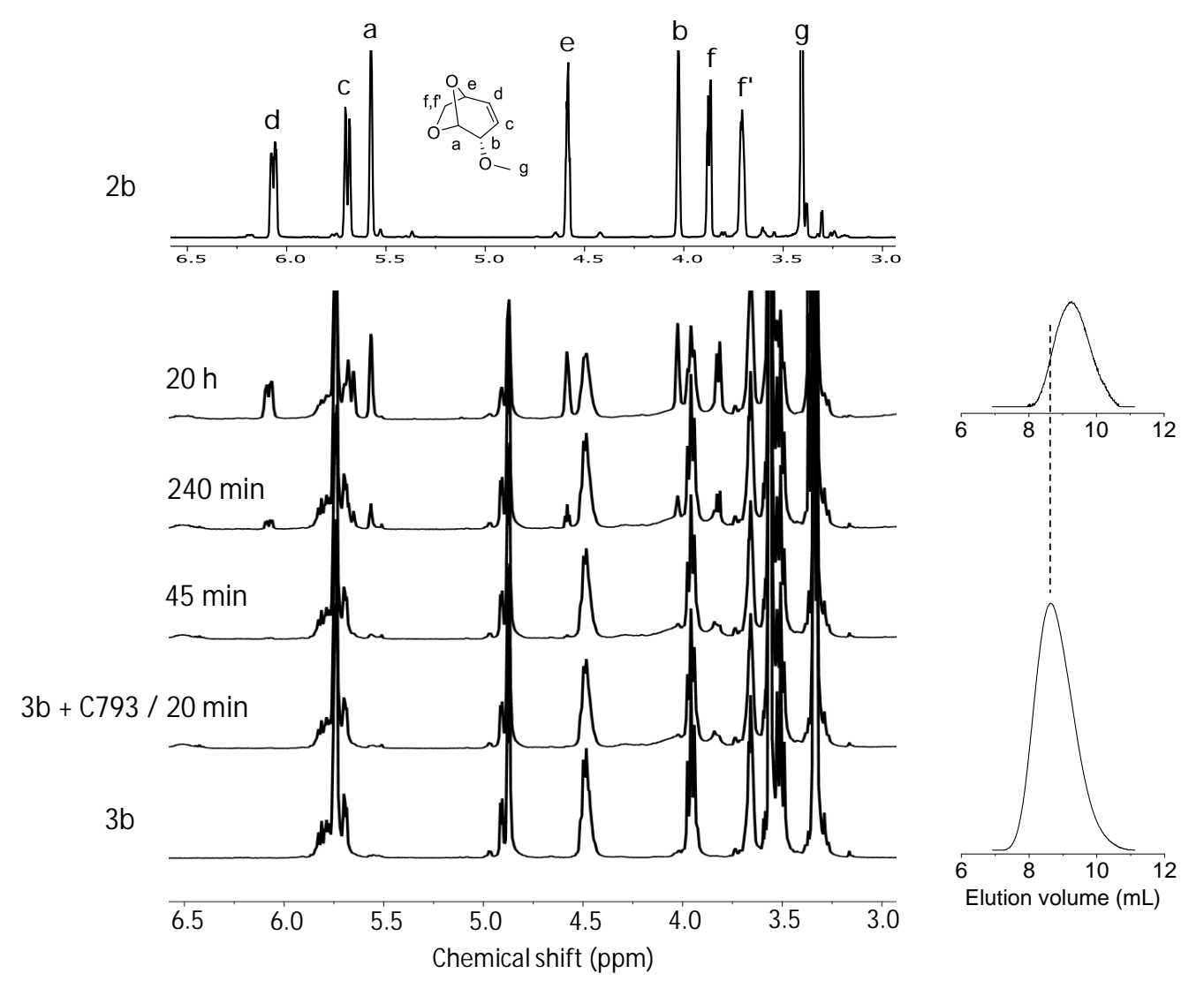

Figure S63. (Left) ${ }^{1} \mathrm{H}$ NM R spectra (400 M Hz) (expanded region 6.5-3.0 ppm) of levoglucosenyl methyl ether $\mathbf{2} \mathbf{b}$ in $\mathrm{CDCl}_{3}$ and of an isolated poly(levoglucosenyl methyl ether) $\mathbf{3} \mathbf{b}$ before and after treatment with catalyst C793 (3b $10 \mathrm{mg}, 0.07 \mathrm{mmol}$ monomer unit, C793 $11 \mathrm{mg}, 0.014$ mmol, 1,4-dioxane-d 0.5 $\mathrm{mL}$ ) at room temperature. (Right) SEC-RI traces of polymer $\mathbf{3 b}$ before and after treatment with catalyst C793. 